\title{
Regulation of Sodium-dependent Phosphate Transport in Osteoclasts
}

\author{
Anandarup Gupta, Xiao-Li Guo, Ulises M. Alvarez, and Keith A. Hruska \\ Renal Division, Barnes-Jewish Hospital of St. Louis, Washington University School of Medicine, St. Louis, Missouri 63110
}

\begin{abstract}
Osteoclasts are the primary cells responsible for bone resorption. They are exposed to high ambient concentrations of inorganic phosphate $(\mathrm{Pi})$ during the process of bone resorption and they possess specific Pi-transport system(s) capable of taking up Pi released by bone resorption. By immunochemical studies and PCR, we confirmed previous studies suggesting the presence of an Na-dependent Pi transporter related to the renal tubular "NaPi" proteins in the osteoclast. Using polyclonal antibodies to $\mathrm{NaPi}-2$ (the rat variant), an $\sim 95-\mathrm{kD}$ protein was detected, localized in discrete vesicles in unpolarized osteoclasts cultured on glass coverslips. However, in polarized osteoclasts cultured on bone, immunofluorescence studies demonstrated the protein to be localized exclusively on the basolateral membrane, where it colocalizes with an $\mathrm{Na}-\mathrm{H}$ exchanger but opposite to localization of the vacuolar H-ATPase. An inhibitor of phosphatidylinositol 3-kinase, wortmannin, and an inhibitor of actin cytoskeletal organization, cytochalasin D, blocked the bone-stimulated increase in Pi uptake. Phosphonoformic acid (PFA), an inhibitor of the renal NaPi-cotransporter, reduced NaPi uptake in the osteoclast. PFA also elicited a dose-dependent inhibition of bone resorption. PFA limited ATP production in osteoclasts attached to bone particles. Our results suggest that $\mathrm{Pi}$ transport in the osteoclast is a process critical to the resorption of bone through provision of necessary energy substrates. (J. Clin. Invest. 1997. 100: 538-549.) Key words: osteoclasts $•$ Na-dependent phosphate cotransporter • phosphatidylinositol 3-kinase - phosphonoformic acid $\bullet$ bone resorption
\end{abstract}

\section{Introduction}

Phosphate is the basic anionic component of the mineralized bone matrix. Osteoblasts are responsible for phosphate deposition in bone, whereas osteoclasts (OCs) $)^{1}$ are involved in re-

Address correspondence to Keith A. Hruska, M.D., Renal Division, Barnes-Jewish Hospital of St. Louis, Washington University Medical Center, 216 South Kingshighway, St. Louis, MO 63110. Phone: 314454-7771; FAX: 314-454-5126; E-mail: khruska@imgate.wustl.edu

Received for publication 2 December 1996 and accepted in revised form 22 April 1997.

1. Abbreviations used in this paper: BS, blocking solution; GLUT4, basal plasma membrane glucose transporter; H-ATPase, protein-ATPase; NaPi, Na-dependent phosphate cotransporter; NHE-1, Na-H exchanger isoform 1; OC, osteoclast; PFA, phosphonoformic acid; Pi, inorganic phosphate; PI 3-K, phosphatidylinositol 3-kinase; $x z$, cross section.

J. Clin. Invest.

(C) The American Society for Clinical Investigation, Inc. 0021-9738/97/08/0538/12 \$2.00

Volume 100, Number 3, August 1997, 538-549

http://www.jci.org sorption of the mineral and matrix components of bone (1). Bone mineral is primarily hydroxyapatite, $\mathrm{Ca}_{3}\left(\mathrm{PO}_{4}\right)_{2} \mathrm{Ca}(\mathrm{OH})_{2}$, an alkaline salt, and hence its dissolution requires protonation, furnished by the proton-ATPase (H-ATPase) on the ruffled membrane of the OC (2). As a result of resorption, OCs are exposed to high ambient concentrations of inorganic phosphate $(\mathrm{Pi})$ from the dissolution of bone mineral. Therefore, to meet the rather immense energy requirements of the OC during the cyclical processes of migration, attachment, and resorption, these cells may possess specific transport mechanisms related to Pi utilization and ATP production. The OC maintains a high demand for ATP $(1,3)$ even when it is not secreting protons, due in part to the energy demands of motility.

Several renal Na-dependent phosphate-cotransporters (NaPi) have been cloned and characterized from the rabbit and other species using the Xenopus oocyte expression cloning system (4-7). Variants of the renal NaPi have been assigned numbers on the basis of species, i.e., NaPi-1 and NaPi-6 in the rabbit, $\mathrm{NaPi}-2$ in the rat, NaPi-3 in the human renal cortex, NaPi-4 in the opossum kidney cell, $\mathrm{NaPi}-5$ in the flounder, and $\mathrm{NaPi}-7$ in the mouse. Based upon overall identity of the variants, the $\mathrm{NaPis}$ have been grouped into either type I ( NaPi-1) or type II (NaPi-2 to-7) families. Polyclonal antibodies have been raised against synthetic $\mathrm{NH}_{2}$ - and $\mathrm{COOH}$-terminal peptides of $\mathrm{NaPi}-2$ which has permitted immunochemical detection of the variants of the NaPis across species (8). While the type I and II NaPis are expressed mainly in the kidney, a third family of $\mathrm{NaPi}$ (type III) has been described recently (9). The cell surface receptors for gibbon ape leukemia virus (Glvr-1, Pit-1) and rat amphotropic virus (Ram-1, Pit-2) were demonstrated to serve normal cellular functions as NaPis. In contrast to the type I and II families, both Pit-1 and -2 are widely distributed, in addition to their presence in the kidney. The highest expressions are in the liver, lung, striated muscle, heart, brain, and bone marrow. Osteoblasts have been shown to express the type III family of NaPis.

We have previously reported preliminary observations characterizing Na-dependent Pi transport in the OC (10). We reported cross-reactivity between a protein in OC lysates and in membrane fractions and an antipeptide antibody to an $\mathrm{NH}_{2}-$ terminal segment of NaPi-2. Immunolocalization studies revealed that the $\mathrm{OC}$ anti-NaPi-2 immunoreactive protein was located largely in a cytosolic vesicular compartment in cells cultured on glass; but upon attachment to bone, plasma membrane expression increased noticeably in the plasma membrane not in contact with bone. In this study, we provide additional evidence for an NaPi-2-like protein in the OC with a significantly larger apparent molecular size than the rodent kidney protein, and present initial studies suggesting a mechanism of NaPi-2-containing vesicular traffic to the plasma membrane in the presence of bone. Most importantly, we demonstrate that a specific inhibitor of the renal $\mathrm{NaPi}-2$ protein also inhibits OC Na-dependent Pi transport, and by so doing decreases bone resorption. We hypothesize that upon attachment to bone the polarization of the $\mathrm{OC}$ is associated with redistribution of the NaPis from discrete vesicular pools into the baso- 
lateral plasma membrane, and that Pi transport is critical for bone resorption.

\section{Methods}

\section{Materials}

Phosphonoformic acid (PFA), colchicine, wortmannin, Ricin-TRITC, and other fluorescent-conjugated antibodies were purchased from Sigma Chemical Co. (St. Louis, MO). The $\left[{ }^{3} \mathrm{H}\right]$-proline-labeled rat bone chips used in bone resorption assays were provided by Dr. S.L. Teitelbaum (Department of Pathology, Washington University School of Medicine, St. Louis, MO). The polyclonal antibodies to either the $\mathrm{NH}_{2}$ terminus of NaPi-2 (MMSYSERLGGPAV) or the COOH terminus of NaPi-2 (LALPAHHNATRL) were provided by Dr. Heini Murer and Dr. Jürg Biber (Institute of Physiology, University of Zurich, Zurich, Switzerland). The monoclonal antibody E11 directed toward the $31-\mathrm{kD}$ subunit of vacuolar H-ATPase was used as ascites fluid provided by Dr. S.L. Gluck (Renal Division, Washington University School of Medicine, St. Louis, MO). The monoclonal antibody to Na-H exchanger isoform 1 (NHE-1) was provided by Dr. D. Biemesderfer (Department of Nephrology, Yale University School of Medicine, New Haven, CT). $\mathrm{K}_{2} \mathrm{H}^{32} \mathrm{PO}_{4}$ was obtained from ICN Biomedicals Inc. (Costa Mesa, CA). The rabbit OC cDNA library was a kind gift of Dr. M. Kumagawa (Sakado, Japan). Dentine slices were used for the immunofluorescent experiments. Both endoglycosidase $\mathrm{H}$ (endo- $\beta-N$-acetylglucosaminidase $\mathrm{H}$ ) and $N$-glycosidase $\mathrm{F}$ were purchased from Boehringer Mannheim (Indianapolis, IN). All other reagents were of analytical grade quality and were purchased from Sigma Chemical Co.

\section{OC cell culture}

Avian OCs. Avian bone marrow macrophage precursors which differentiate into OCs were isolated from calcium-deprived hens and cultured as previously described (11). Briefly, laying hens were maintained on a calcium-free diet (Ralston Purina Co., St. Louis, MO) for 3 to $4 \mathrm{wk}$, at which time bone marrow was harvested. Mononuclear cells were isolated by Ficoll-Hypaque gradient centrifugation (Litton Bionetics, Rockville, MD) and the cells adherent at $24 \mathrm{~h}$ were cultured at $2.5 \times 10^{7} / 25 \mathrm{~cm}^{2}$ in $\alpha$-MEM plus $5 \%$ FCS plus $5 \%$ chicken serum, $100 \mu \mathrm{g} / \mathrm{ml}$ streptomycin, $100 \mathrm{IU} / \mathrm{ml}$ penicillin, and $3 \mu \mathrm{g} / \mathrm{ml} \mathrm{cy-}$ tosine $1 \beta$-D arabino furanoside. Temperature was maintained at $39^{\circ} \mathrm{C}$ in a water-saturated atmosphere containing $10 \% \mathrm{CO}_{2}$. Under these conditions, the cells (OC precursors) fused within 3-5 d forming an $85-95 \%$ pure population of multinucleated cells. The cells were characterized as having an $\mathrm{OC}$ phenotype by a variety of functional, morphological, and immunohistochemical criteria. Functionally, the OC precursors differentiated in culture and formed resorption pits when added to bone slices. Morphologically, they expressed ruffled borders upon attachment to bone and were uniformly TRAP (tartrate resistant acid phosphatase) positive. They expressed several OC-specific antigens detected by monoclonal antibodies. Therefore, the multinucleated OCs were formed in culture and not directly isolated from bone.

Rabbit OCs. Unfractionated bone cells were isolated from long bones of 7-d-old rabbits, as previously described (12). The bone cells were disaggregated in $\alpha$ MEM; bone particles were removed by sedimentation under normal gravity. Cells were suspended in $\alpha \mathrm{MEM}$ supplemented with $10 \%$ FCS and seeded into culture plates. After $3 \mathrm{~h}$ of culture, the medium was exchanged for fresh medium and after an additional $21 \mathrm{~h}$ of culture, the cells were washed with PBS to remove nonadherent cells. Subsequently, the cells were washed with PBS plus $0.001 \%$ Pronase E plus $0.02 \%$ EDTA for $10 \mathrm{~min}$ at $37^{\circ} \mathrm{C}$. The stromal cells were removed by washing several times and the remaining cells comprised $\sim 95 \%$ pure OCs, positive for TRAP activity (13).

Mouse OCs. The tibiae and femurs of 7-wk-old mice were used to isolate bone cells, as previously described (13). The cells were suspended in $\alpha \mathrm{MEM}$ and cultured at $37^{\circ} \mathrm{C}$ in a $5 \% \mathrm{CO}_{2}$ incubator. M-CSF-1 was added to the cultures at a concentration of $1,000 \mathrm{U} / \mathrm{ml}$ and the nonadherent cells were removed after $24 \mathrm{~h}$. The cells were suspended in a Ficoll-Hypaque gradient (Litton Bionetics) and the interface removed and suspended in $\alpha$ MEM. ST-2 stromal cells were added at a seeding density ratio of 1:10 in the presence of dexamethasone $(10 \mu \mathrm{M}), 1,25(\mathrm{OH})_{2} \mathrm{D}_{3}(10 \mathrm{nM})$, and M-CSF-1. The cultures were maintained for 10 to $12 \mathrm{~d}$; subsequently, the stromal cells were removed by collagenase treatment. The remaining adherent cells were pure mouse OCs, as previously described (13).

\section{Pi transport studies}

Avian OCs were plated in 24-well dishes and washed with the incubation buffer which contained (mM): $150 \mathrm{NaCl}$ (or choline chloride), $5 \mathrm{KCl}, 1.8 \mathrm{MgSO}_{4}, 1 \mathrm{CaCl}_{2}, 10$ Hepes, $0.1 \mathrm{~K}_{2} \mathrm{H}^{32} \mathrm{PO}_{4}$, and 5 glucose at $\mathrm{pH}$ 7.4. $1 \mathrm{ml}$ of Pi uptake assay buffer $\left({ }^{32} \mathrm{Pi}, 1 \mu \mathrm{Ci} / \mathrm{ml}\right)$ was added to the incubation buffer for varying periods of time at room temperature. After the specified time intervals, the cells were washed with ice-cold incubation buffer followed by solubilization in $0.2 \mathrm{~N} \mathrm{NaOH}$. Pi uptake was determined by liquid scintillation counting. Protein contents were determined for each time point for normalization of the counts (cpm) obtained from Pi uptake studies. The raw data (in $\mathrm{cpm}$ ) were transformed (to $\mu \mathrm{mol}$ of $\mathrm{Pi}$ ) and presented as $\mu \mathrm{mol} / \mathrm{mg}$ protein, as previously described (10).

\section{Western blot analysis}

Chicken OCs were used on day 5 in culture for preparation of crude membrane fractions. The cells were first washed twice with PBS and then lysed in homogenization buffer which contained (mM): 15 Tris, $\mathrm{pH} 7.5,0.25$ sucrose, $2.5 \mathrm{MgCl}_{2}$, and 2.5 EGTA. Briefly, the cells were homogenized using a Dounce homogenizer, and then the homogenate was centrifuged at $10,000 \mathrm{rpm}$ for $10 \mathrm{~min}$ in a rotor (Sorvall SS34; DuPont Co., Wilmington, DE). The supernatant was collected and ultracentrifuged at 40,000 rpm in a rotor (Ti 70.1; Beckman Instruments, Schaumburg, IL) for $1 \mathrm{~h}$ at $4^{\circ} \mathrm{C}$. The pellet containing the membrane fractions was solubilized in sample buffer containing $2 \%$ SDS, as previously described (14). The protein contents were determined using the BCA protein assay (Pierce Chemical Co., Rockford, IL) and equal amounts of proteins were loaded per lane $(100 \mu \mathrm{g})$, and were analyzed by SDS-PAGE on $8 \%$ gels. The gel was then electroblotted onto a PVDF membrane (Millipore, Bedford, MA) by wet-dry transfer (Enprotech; Integrated Separation Systems, Natick, MA). Nonspecific protein binding was blocked with $5 \%$ nonfat dry milk powder dissolved in PBS containing $0.1 \%$ Tween 20 . The blots were incubated overnight with a 1:1,000 dilution of the primary antibodies to $\mathrm{NaPi}-2\left(\mathrm{NH}_{2}\right.$ or $\mathrm{COOH}$ terminus). This was followed by detection with a horseradish peroxidase-conjugated secondary goat anti-rabbit antibody (Sigma Chemical Co.; 1:1,000 dilution). The secondary antibody (horseradish peroxidase-conjugated goat anti-rabbit antibody) was detected by the enhanced chemiluminescence detection kit (Amersham Corp., Arlington Heights, IL) following the manufacturer's instructions. In those experiments where (surface) biotinylated membranes were used, intact chicken OCs were first washed twice with PBS supplemented with $\mathrm{CaCl}_{2}(0.1 \mathrm{mM})$ and $\mathrm{MgCl}_{2}(1.0 \mathrm{mM})$. The OCs were labeled for $30-60 \mathrm{~min}$ at $4^{\circ} \mathrm{C}$ with $0.5 \mathrm{mg} / \mathrm{ml}$ sulfo-NHSLC-biotin (i.e., the water soluble $N$-hydroxysuccinimide long chain ester of biotin; Pierce Chemical Co.) freshly diluted into biotinylation buffer which consisted of PBS with $1 \mathrm{mM}$ EDTA. The cells were then washed twice for $20 \mathrm{~min}$ at $4^{\circ} \mathrm{C}$ with ice-cold PBS containing $5 \mathrm{mM}$ glycine to quench the unreacted biotin. After two more rinses with PBS, the cells were solubilized on ice with lysis buffer containing (mM): $150 \mathrm{NaCl}, 20$ Tris, $2 \mathrm{mM}$ EDTA, and 0.5\% NP-40, at $\mathrm{pH} 7.4$. After determination of protein content, the lysates were incubated with avidin agarose (Pierce Chemical Co.). The avidin-agarose immunoprecipitates were washed three times with lysis buffer and twice with $20 \mathrm{mM}$ Tris- $\mathrm{HCl}, \mathrm{pH}$ 7.5. The samples were then solubilized in Laemmli sample buffer and boiled for $15 \mathrm{~min}$ to dissociate the avidin-biotin complex. The biotinylated proteins were separated on an $8 \%$ SDS-PAGE. Thereafter, standard immunoblotting techniques were used, as described above. 


\section{Immunostaining}

Avian OCs were plated in 4-well Lab-Tek (Nunc Inc., Naperville, IL) culture chambers and cells were used on day 5 of culture when most cells were mature multinucleated OCs, as previously described (14). Rabbit OCs were studied on day 3 of culture. The cells were briefly rinsed twice in ice-cold PBS and then fixed and permeabilized with $100 \%$ methanol at $-80^{\circ} \mathrm{C}$. The cells were blocked with blocking solution (BS) which comprised PBS containing $20 \%$ goat serum and $1 \%$ polyethylene glycol for 1-2 $\mathrm{h}$. The cells were incubated overnight in a 1:500 dilution of the various primary antibodies at $4^{\circ} \mathrm{C}$ in the $\mathrm{BS}$ described above. After two 15-min rinses with PBS with $0.1 \%$ Tween 20 , the cells were further incubated with FITC-conjugated goat antirabbit antibodies in BS for $2 \mathrm{~h}$. The cells were washed with PBS and then mounted with VectaShield ${ }^{\mathrm{TM}}$ (Vector Laboratories, Inc., Burlingame, CA). Negative controls were performed with nonimmune rabbit sera in the BS formulation described above. Double-label immunofluorescence microscopy was performed using a confocal laser scanning microscope (Carl Zeiss, Inc., Thornwood, NY). Briefly, photomicrographs were obtained with a scanning laser confocal microscope system (LSM 410; Carl Zeiss, Inc.). The system consisted of an inverted microscope (135 Axiovert; Carl Zeiss, Inc.) fitted with an Omnicron argon/krypton laser for confocal excitation. Samples were viewed with a $63 \times / 1.25$ n.a. oil objective, and images were recorded in a $512 \times 512$ pixel format. FITC images were recorded using the 488 $\mathrm{nm}$ argon excitation line, whereas the Texas red images were recorded with the 568 argon excitation line. The data were collected as emission intensities using barrier filters for FITC (515-540 nm bandpass) and Texas red (590-640 nm bandpass). Data processing was accomplished with the LSM 410 software package (Carl Zeiss, Inc.). Photomicrographs were produced from a color video printer (Mavigraph; Sony Corp., Park Ridge, NJ) or stored in TIF image format for post processing, as previously described $(10,14)$.

\section{$P C R$ of rabbit $O C D N A$}

A sequence of the rabbit osteoclastic NaPi- 6 was amplified by PCR from a randomly primed ZapII cDNA library generated from rabbit OCs (12). Primers for the NaPi were synthesized from two regions highly conserved among the NaPi-2 and NaPi-6 species isoforms (5): sense primer ${ }^{5}$ CCACCATGGAGAAATGCAA (1063-1081 from $\mathrm{NaPi}-6)$ and antisense primer ${ }^{5}$ CCCGAGATGTTGAAGAAGAAGTG (1500-1522 from NaPi-6). Amplifications were carried out with standard methods using $5 \mu \mathrm{l}$ of the amplified library $\left(10^{10}\right.$ plaque forming units $/ \mathrm{ml}$ ) as template. Reactions were denatured at $94^{\circ} \mathrm{C}$ for $0.5 \mathrm{~min}$, annealed at $49^{\circ} \mathrm{C}$ for $1 \mathrm{~min}$, and elongated at $72^{\circ} \mathrm{C}$ for $3 \mathrm{~min}$ with a total of 35 cycles (15). The expected size product (460 bp) was obtained from both sets of primers and ligated with PCRII vector (Invitrogen Corp., San Diego, CA). Sequences were determined from both ends from individual clones using the dideoxynucleotide chain termination method of Sanger et al. (16).

\section{Bone resorption assay}

$\left[{ }^{3} \mathrm{H}\right]$ Proline-prelabeled bone release. Chicken and mouse OCs were cultured in the presence of bone chips for $5 \mathrm{~d}$ in 24-well plates. On day 1 of the experiments, $\left[{ }^{3} \mathrm{H}\right]$ proline-prelabeled devitalized rat bone chips $\left(2.5 \times 10^{5} \mathrm{cpm} /\right.$ well $)$ were added. On day 3 , PFA was added at the individual concentrations of 1,2 , and $5 \mathrm{mM}$ to each well. $1.0 \mathrm{ml}$ of the culture media was sampled on both days 4 and 5 to assess the amount of ${ }^{3} \mathrm{H}$-bone being resorbed. After the last sampling period, the cells were lysed with $0.2 \mathrm{~N} \mathrm{NaOH}$ and assayed for protein content. Bone resorption was represented by $\mathrm{cpm}\left[{ }^{3} \mathrm{H}\right]$ proline/mg protein, and as percentage of control.

Pit assay. Chicken OC precursors were allowed to differentiate on osteologic discs (Millenium Biologix Inc., Kingston, Ontario, Canada) coated with a $1-\mu \mathrm{m}$-thick calcium phosphate film. On day 3 of culture, PFA was added at the individual concentrations of 1,2 , and 5 $\mathrm{mM}$ to each well. After $48 \mathrm{~h}$ in culture, on day 5 , the discs were washed with bleach to remove all adherent OCs. The discs were then washed in water and allowed to air dry before they were examined for bone resorption, as previously described (17).

\section{Adenosine-5'-triphosphate (ATP) assay}

Chicken OC precursors were allowed to differentiate into multinucleated OCs for $4 \mathrm{~d}$ in 24-well plates. On day 4, parallel sets of cultures were incubated with 1,2 , and $5 \mathrm{mM}$ PFA in the absence and presence of $\left[{ }^{3} \mathrm{H}\right]$ proline-prelabeled devitalized rat bone chips $\left(2.5 \times 10^{5} \mathrm{cpm} /\right.$ well). After $48 \mathrm{~h}$ in culture, the OCs were processed for assay of total ATP content according to methods described by Adams (18), and following the manufacturer's instructions (Sigma Chemical Co., St. Louis, MO). In the described procedure, phosphoglycerate phosphokinase is used to catalyze the reaction: ATP +3 -phosphoglycerate $\rightarrow$ ADP + 1,3-diphosphoglycerate; the enzyme glyceraldehyde phosphate dehydrogenase is also present in the reaction mixture to catalyze the following: 1,3-diphosphoglycerate $+\mathrm{NADH} \rightarrow$ glyceraldehyde-3-P + $\mathrm{NAD}+\mathrm{P}$. By determining the decrease in absorbance at $340 \mathrm{~nm}$ that results when $\mathrm{NADH}$ is oxidized to NAD, a measure of the amount of ATP originally present is obtained. Briefly, the cells were washed twice with ice-cold PBS before lysis in $2 \mathrm{ml}$ of lysis buffer containing (mM): $150 \mathrm{NaCl}, 20$ Tris, $2 \mathrm{mM}$ EDTA, and $0.5 \% \mathrm{NP}-40$, $\mathrm{pH}$ 7.4. After lysis, $1 \mathrm{ml}$ of the OC lysate was added to $1 \mathrm{ml}$ of $12 \%$ TCA on ice for $10 \mathrm{~min}$ to precipitate the proteins in the cell lysates. The samples were then centrifuged at $3,000 \mathrm{rpm}$ for $10 \mathrm{~min}$ to obtain a clear supernatant. The reaction mixture comprised $1.0 \mathrm{ml}$ of a buffered solution of 3-phosphoglyceric acid, $0.5 \mathrm{ml}$ of the supernatant, $0.3 \mathrm{mg} \mathrm{NADH}$, and $1.5 \mathrm{ml} \mathrm{H}_{2} \mathrm{O}$ (total volume: $3 \mathrm{ml}$ ). The initial absorbance of this reaction mixture was recorded at $340 \mathrm{~nm}$. Subsequently, $40 \mu 1$ of glyceraldehyde phosphate dehydrogenase/phosphoglycerate phosphokinase ( 800 and $450 \mathrm{U} / \mathrm{ml}$, respectively) enzyme mixture was added to the reaction mixture and the final minimum absorbance (at $340 \mathrm{~nm}$ ) was recorded. Thereafter, the absorbance readings were converted to $\mathrm{nmol} \mathrm{ATP} / \mu \mathrm{g}$ protein after determination of protein content and, subsequently converted to percentage of control for presentation.

\section{Statistics}

The statistical computation for the "bone resorption" assay was done as follows: the raw data points $\left({ }^{3} \mathrm{H}-\mathrm{cpm} / \mathrm{ml}\right)$ for the bone resorption assay were used to obtain the mean for the (untreated) control group. Each raw data point within that group was divided by the mean and subsequently transformed (multiplying the quotient by 100) to get percentage of control for each data point within that group. From these transformed data points, we determined the mean \pm SEM for the control group. To obtain similar data for the experimental treatment groups, each raw data point was divided by the original mean of control group; the quotients were similarly transformed into percentage of control. Therefore, similar to that for the control group, means \pm SEM were obtained for the experimental groups. For all other experiments, statistical comparisons were performed on means \pm SEM and differences between means were considered significant at $P<0.01$, using the Student's $t$ test.

\section{Results}

Immunochemical characterization of the NaPi. We have extended our preliminary characterization of the immunochemical identity of the NaPi in the OC (10) which was based on the detection of an $\mathrm{OC}$ protein by an $\mathrm{NH}_{2}$-terminal antipeptide $\mathrm{NaPi}-2$ antibody (8). Since the protein detected was larger than the expected size from the renal tubule NaPi-2, it was critical to obtain further evidence that the detected protein was in fact NaPi-related. We performed peptide competition studies and used a second antibody directed against the $\mathrm{COOH}$ terminus of the NaPi-2 molecule. As shown in Fig. 1, both the $\mathrm{NH}_{2}$ and $\mathrm{COOH}$-terminal antipeptide antibodies detected proteins of the same molecular size, and peptide competition studies using the respective $\mathrm{NaPi}-2 \mathrm{NH}_{2}$ terminus peptide completely 


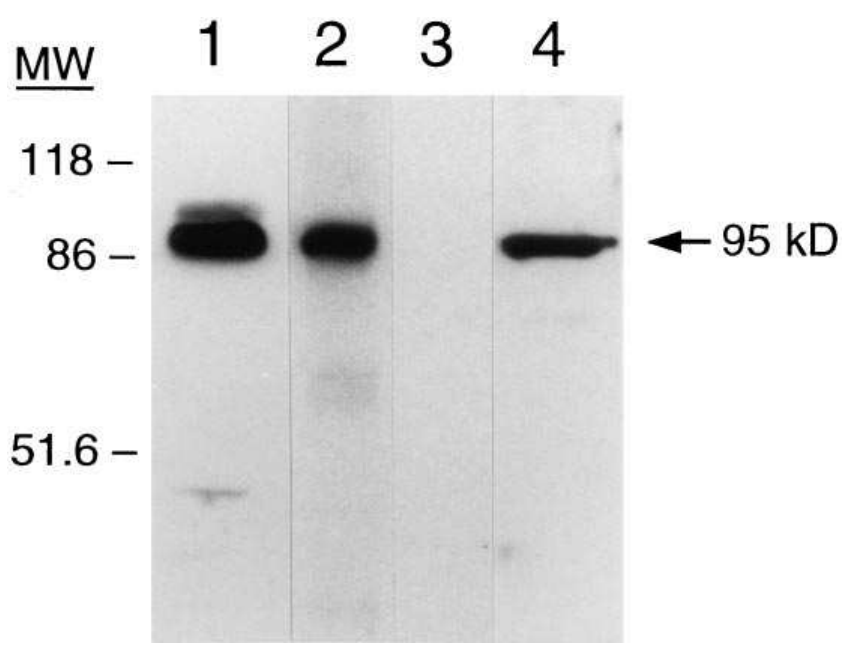

Figure 1. Detection of NaPi in avian OCs. Membrane fractions and total cell lysates prepared from avian OCs were separated on an $8 \%$ SDS-PAGE for immunoblotting with NaPi-2 antibodies. Lane 1: immunoblot of biotinylated plasma membranes with an antibody toward the $\mathrm{NH}_{2}$ terminus of NaPi-2. The apparent molecular mass of the detectable band in lane 1 is $\sim 95 \mathrm{kD}$. Lane 2: immunoblot of total $\mathrm{OC}$ lysates with the $\mathrm{NH}_{2}$-terminal antibody for NaPi-2. Lane 3: specificity of the band detected in lane 2 was demonstrated by preincubation of the $\mathrm{NH}_{2}$-terminal antibody with $100 \mu \mathrm{g} / \mathrm{ml}$ of the $\mathrm{NH}_{2}$-terminal synthetic peptide. Lane 4: immunoblot of total OC lysates with an antibody toward the $\mathrm{COOH}$ terminus of $\mathrm{NaPi}-2$.

blocked detection of the protein. A $95-\mathrm{kD}$ band was detected in chicken microsomal fractions (lane 1) and in whole cell lysates (lane 2) by the $\mathrm{NH}_{2}$-terminal antibody. We have reported previously that a protein of the same molecular size was detected in rabbit OC lysates by the $\mathrm{NH}_{2}$-terminal antibody (10). The NaPi-2-like protein detected in total chicken OC lysates with an antibody toward the $\mathrm{COOH}$ terminus of $\mathrm{NaPi}-2$ is shown in lane 4 . Since there is $100 \%$ amino acid identity at the $\mathrm{COOH}$ terminus of NaPi-2, $-3,-4$, and -6 (LALPAHHNATRL, 5), this provides further evidence that the OC protein is of the NaPi-2 family. In data not shown, we found that the $\mathrm{NaPi}-2-$ related proteins of the OC were not N-glycosylated, by the lack of susceptibility of the $95-\mathrm{kD}$ band to either endoglycosidase $\mathrm{H}$ or PNGase F, in contrast to that of NaPi-2 (19).

Detection of an NaPi-2-related gene in the rabbit OC. We wished to determine whether an NaPi-2-related protein was present in the OC. Since the species variants of the NaPi (4-7), especially NaPi-2 to -6 , share several conserved domains, we performed PCR using primers flanking a conserved region among NaPi-2 and -6 (rabbit) and a rabbit OC cDNA library (Fig. $2 A$ ). A 460-bp PCR product of identical sequence to NaPi-6 (5) was obtained (Fig. $2 B$ ). As a result of the immunologic cross-reactivity of the two NaPi-2 antibodies to rabbit and avian proteins of the same size, and the presence of a NaPi-6-related cDNA in the OC, we conclude that the 95-kD protein is likely a NaPi-related protein. Since the avian $\mathrm{NaPi}$ protein has probably not been cloned, the corresponding PCR product from the avian OC is not shown.

Cellular distribution of the NaPi in unpolarized OCs. Using immunoblots of microsomal fractions isolated from chicken OCs grown either in the presence or absence of bone in our preliminary studies, we reported that the stimulatory effect of bone particles on Pi uptake by OCs was accompanied by an increased level of expression of the $\mathrm{NaPi}$ in cellular membranes (10). This occurred without a change in the amount of $\mathrm{NaPi}$ protein in total cell lysates in agreement with the inability of actinomycin D or cycloheximide to block the increase in $\mathrm{Na}$ dependent Pi transport induced by the presence of bone, as previously reported (10).

Preliminary immunolocalization studies of the OC NaPi-2like protein using laser scanning confocal microscopy to examine the cellular distribution of the $\mathrm{NaPi}$ in OCs grown on glass revealed staining of a vesicular, possibly endosomal, compartment distributed diffusely throughout the cell. As shown in Fig. 3, when using the $\mathrm{COOH}$-terminal antibody against $\mathrm{NaPi}-2$, a similar distribution of vesicular staining was detected in OCs cultured on glass.

To further characterize the endosomal distribution of the OC NaPi, ricin was used as an endocytic marker. Ricin is a $60-\mathrm{kD}$ lectin which binds to galactose residues of membrane glycoproteins and glycolipids and thereby acts as a probe for membrane traffic (20). Ricin is widely used as a common marker for apical recycling endosomes and recycling of apically internalized membrane proteins in polarized epithelial cells. The majority of apically internalized ricin recycles back to the apical plasma membrane, while a small percentage is transcytosed to the basolateral plasma membrane or transported to the lysosomes and the Golgi complex (20). We hypothesized that an $\mathrm{OC}$ endosomal fraction containing the $\mathrm{NaPi}$ would redistribute when the $\mathrm{OC}$ polarized in response to bone. OCs were treated with TRITC-conjugated ricin for $15 \mathrm{~min}$ at $37^{\circ} \mathrm{C}$. The cells were then fixed and processed for immunostaining with the NaPi-2 antibody. Fig. $4 A$ shows an OC cul-
A

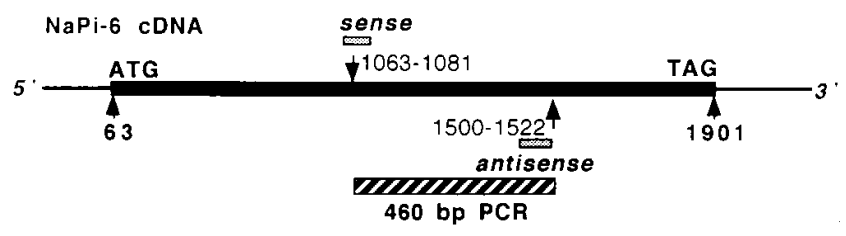

B

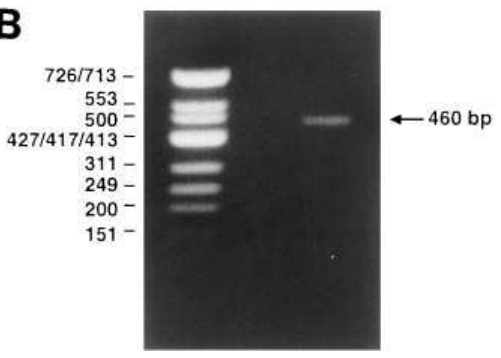

Figure 2. PCR of $\mathrm{NaPi}$ in rabbit OC. $(A)$ A map of the NaPi- 6 cDNA demonstrates the regions from which NaPi-6 cDNA primers for the PCR reactions were derived. (B) PCR of rabbit OC mRNA. An expected 460-bp fragment was detected. The sequence of the PCR fragment was identical to NaPi-6 in the rabbit kidney. 

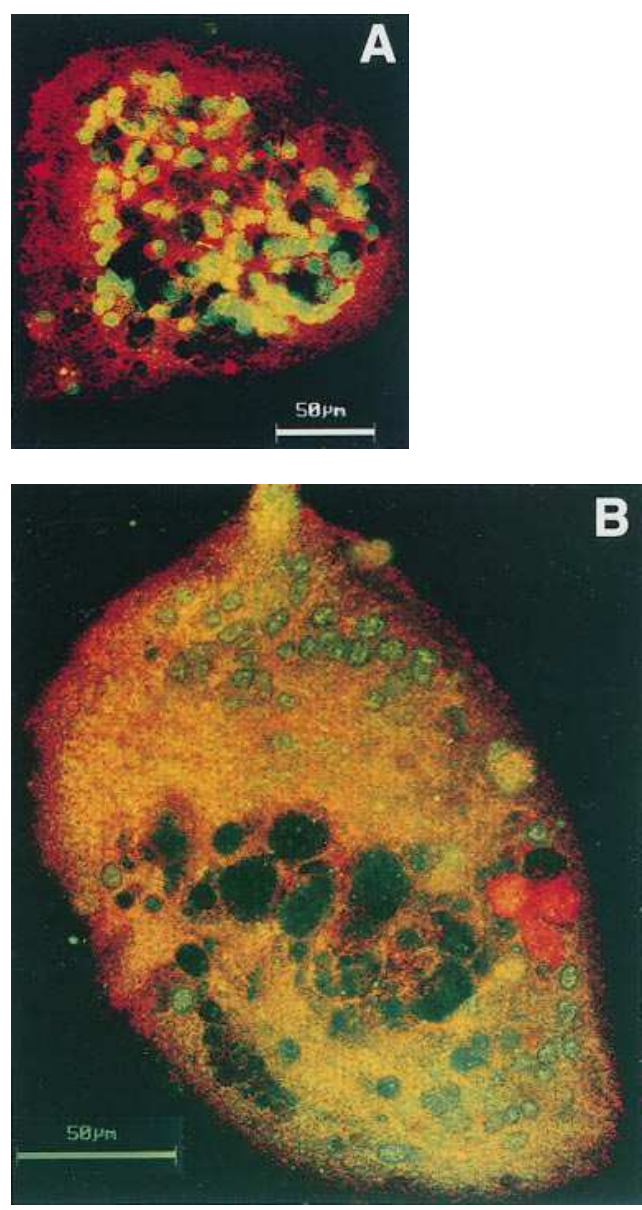

Figure 3. Immunofluorescent localization of $\mathrm{NaPi}$ in the avian $\mathrm{OC}$ using laser scanning confocal microscopy. Avian OCs were cultured on glass coverslips and immunostained with antibodies to $\mathrm{NaPi}-2$ $\left(\mathrm{NH}_{2}\right.$ and $\mathrm{COOH}$ termini). ( $A$ ) An apical (i.e., close to the glass surface) image of an $\mathrm{OC}$; the color red represents the reflection image of the $\mathrm{OC}$ whereas the punctate green staining represents the immunofluorescence obtained with the $\mathrm{NH}_{2}$-terminal $\mathrm{NaPi}$-2 antibody. $(B)$ Apical image of an OC; the color red represents the reflection image of the $\mathrm{OC}$ whereas the punctate green staining represents the immunofluorescence obtained with the $\mathrm{COOH}$-terminal $\mathrm{NaPi}-2$ antibody.
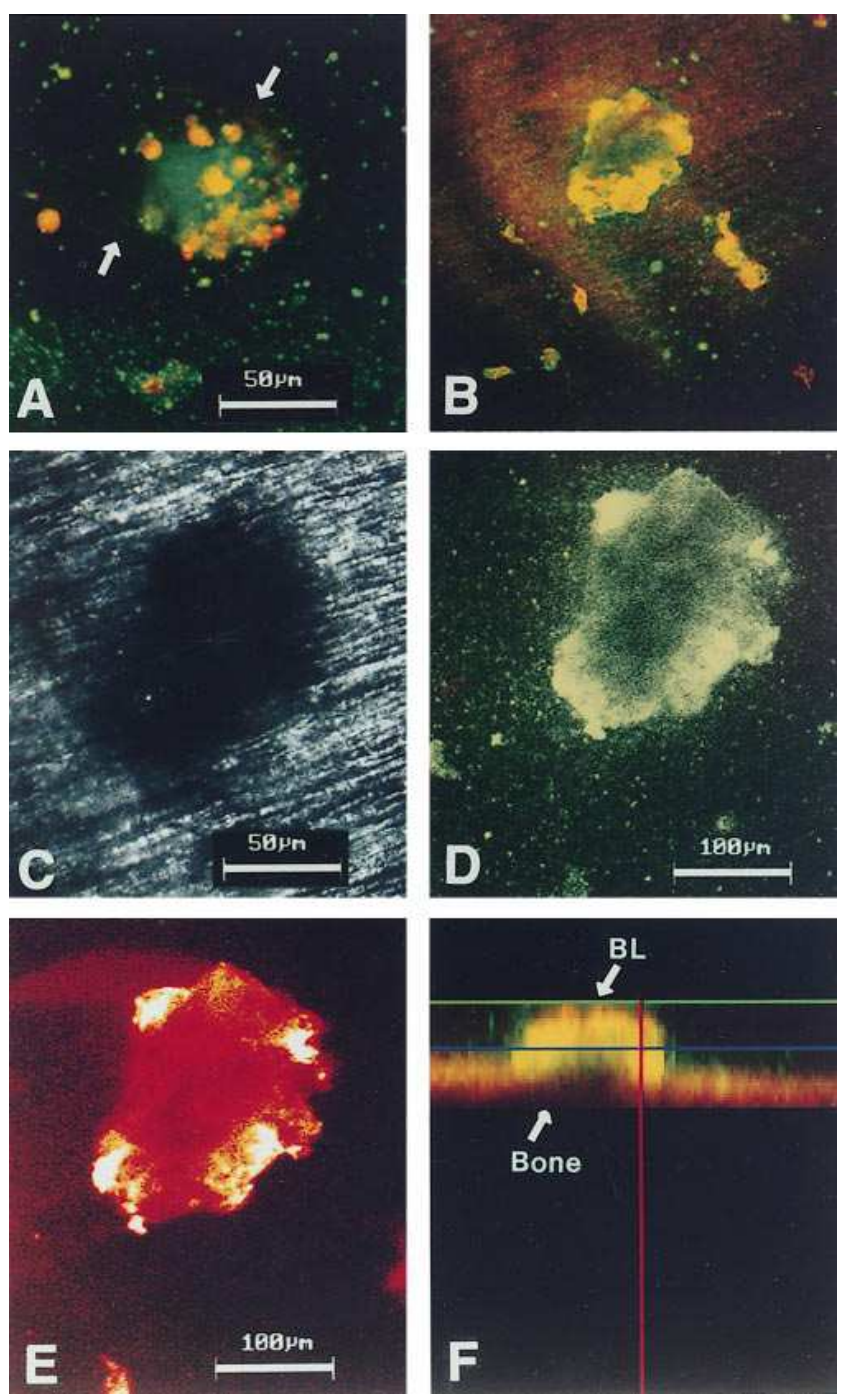

Figure 4. Localization of $\mathrm{NaPi}-2$ protein in endosomes in avian OCs using laser scanning confocal microscopy. $(A)$ Avian OCs cultured on glass and double-stained with both TRITC-conjugated ricin and the $\mathrm{NaPi}-2$ antibody ( $\mathrm{NH}_{2}$ terminus). (B) Avian OCs cultured on bone and double-stained for ricin and $\mathrm{NaPi}-2$ protein $\left(\mathrm{NH}_{2}\right.$ terminus); $C$ shows that the OC in $B$ was positioned on a resorption pit; $(D) \mathrm{Im}-$ munostaining for NaPi-2 and $(E)$ ricin, separately. $(F) x z$ scan of the dual-label immunofluorescence for ricin and $\mathrm{NaPi}-2$, with the arrows pointing toward either the basolateral membrane or the apical surface (facing bone) of the OC.

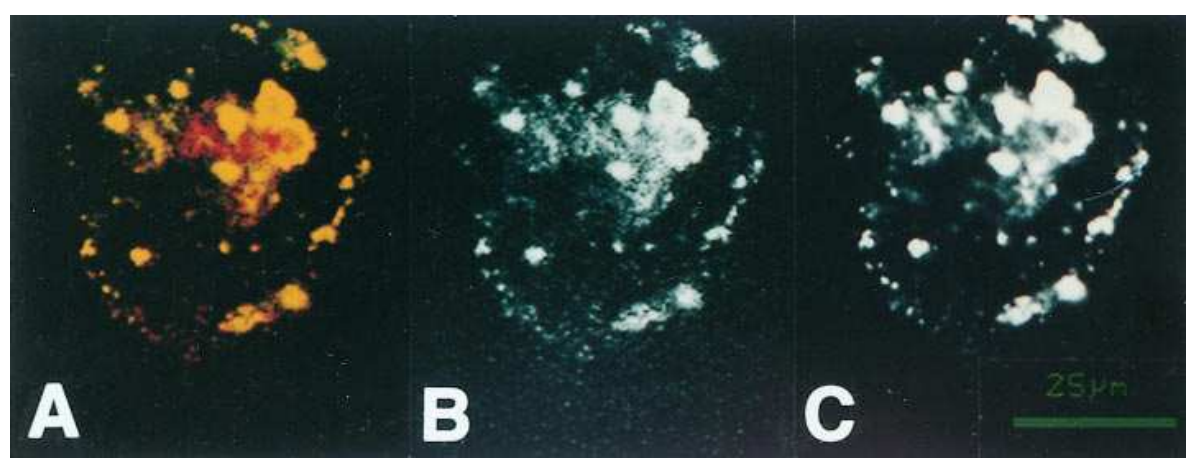

Figure 5. Localization of $\mathrm{NaPi}-2$ protein in endosomes in rabbit OCs using laser scanning confocal microscopy. (A) Apical images of rabbit OCs cultured on glass and double-stained with both TRITC-conjugated ricin and the $\mathrm{NaPi}-2$ antibody ( $\mathrm{NH}_{2}$ terminus). (B) Corresponding immunolocalization of $\mathrm{NaPi}-2$, and $(C)$ ricin, separately. 

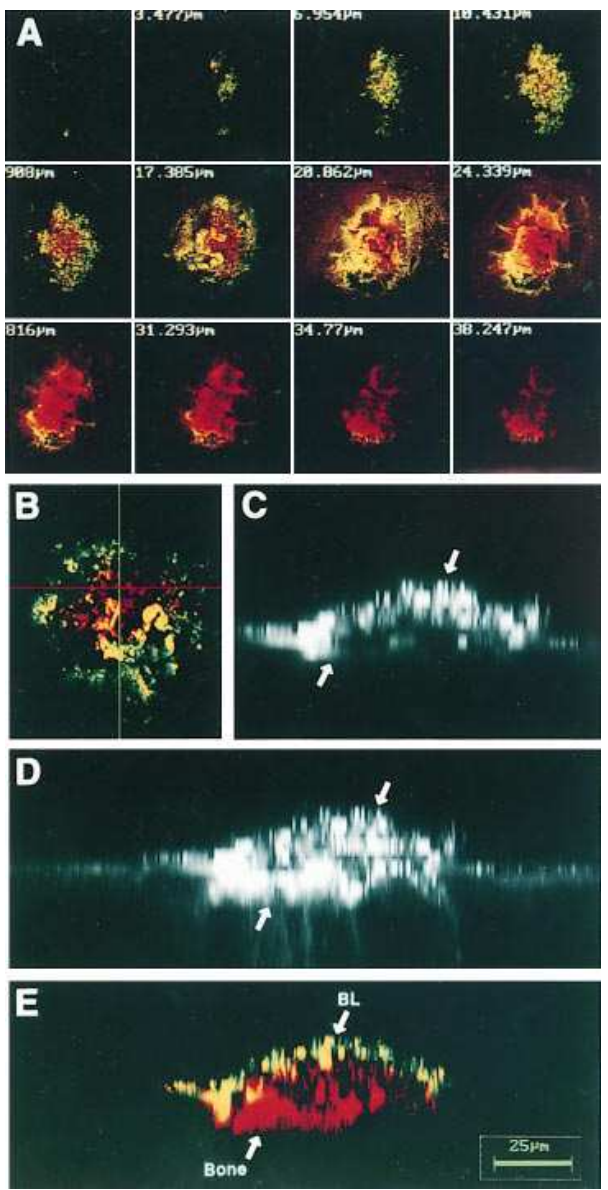

Figure 6. Double-label immunofluorescence for NaPi-2 and H-ATPase in the avian OC. Chicken OCs were cultured on bone and immunostained with the $\mathrm{NaPi}-2$ antibody $\left(\mathrm{NH}_{2}\right.$ terminus) and the antibody E-11 for the H-ATPase. ( $A$ ) Series of basolateral-to-apical scans (4 $\mu \mathrm{m}$ steps) of the avian OC dual stained for both NaPi-2 (FITC) and H-ATPase (Texas red). There is a high degree of colocalization of the two proteins only on the basolateral surface of the OC (pseudocolored yellow). As the bone surface is approached, the immunostaining is distinctly different for the two proteins toward the center of the cell which actually faces a resorption cavity. (B) An apical image of the $\mathrm{OC} \sim 5 \mu \mathrm{m}$ from the surface of bone and the resorption cavity as shown in $A$. This representative focal plane shows the immunostaining pattern for both the H-ATPase and NaPi-2. (C) An $x z$ image of the OC representing the immunostaining for $\mathrm{NaPi}-2$ on the basolateral membrane of the OC. (D) An $x z$ image of the OC representing the immunostaining for H-ATPase; the staining is intense on the membrane facing the resorption cavity. $(E)$ Colocalization of both H-ATPase and NaPi-2 only on the basolateral membrane of the OC (pseudocolored yellow).

tured on glass and double-stained for ricin (TRITC) and NaPi (FITC). There is an almost complete absence of peripheral plasma membrane staining, as indicated by the arrows. Discrete endosomes demonstrating colocalization of the toxin and $\mathrm{NaPi}$ (yellow) were observed in the cytoplasm. An additional pool of NaPi alone (green) is diffusely distributed. OCs cultured on glass are not polarized, but upon attachment to bone they reorganize into highly polarized cells. An OC cultured on bone and double-labeled for ricin and $\mathrm{NaPi}$ is shown in Fig. $4 B$. The pattern of colocalization is very different from that on

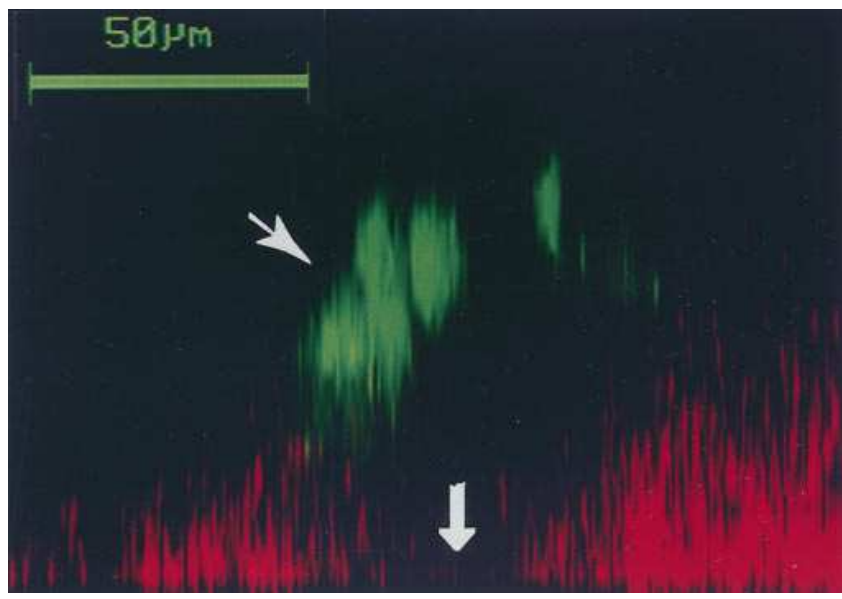

Figure 7. Basolateral location of $\mathrm{NaPi}$ in the polarized rabbit OC. Rabbit OCs were cultured on bone and immunostained with the $\mathrm{NaPi}-2$ antibody ( $\mathrm{NH}_{2}$ terminus). An $x z$ scan of OC stained for the $\mathrm{NaPi}$ (FITC); the top arrow points to the basolateral membrane of the $\mathrm{OC}$, whereas the resorption pit is indicated by the bottom arrow facing downward.
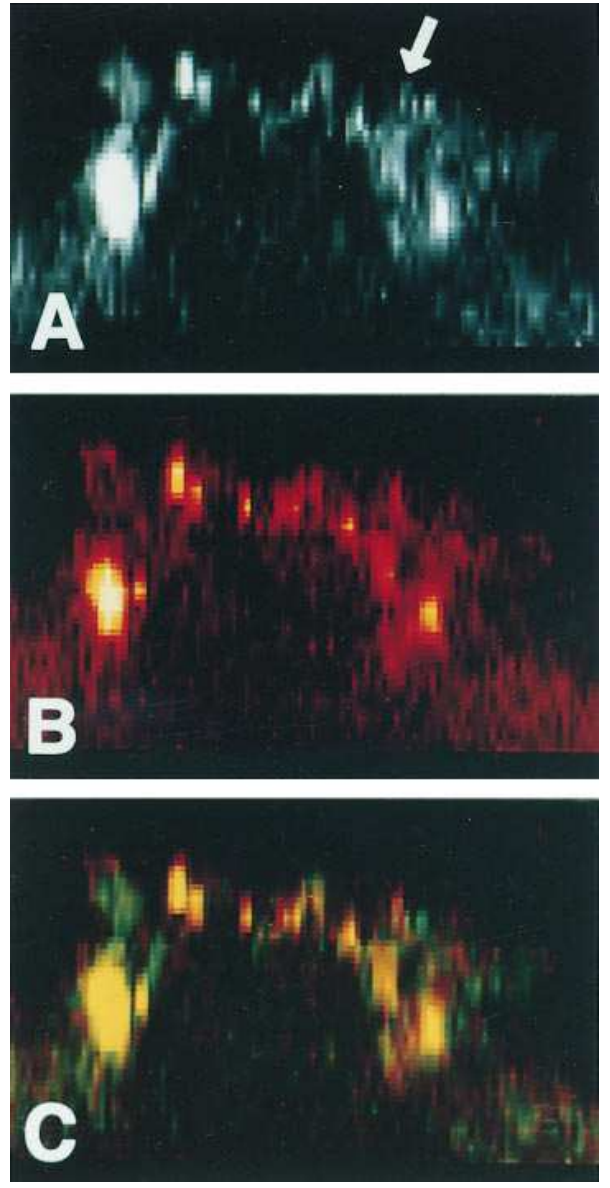

Figure 8. Colocalization of NaPi with the Na-H exchanger (NHE-1 isoform) on the basolateral membrane of avian OCs on bone. Chicken OCs were cultured on bone and immunostained with the NaPi-2 antibody ( $\mathrm{NH}_{2}$ terminus) and antibody $4 \mathrm{E} 9$ for NHE-1. $(A)$ An $x z$ scan of OC stained for the $\mathrm{NaPi}$ (FITC); the arrow points to the basolateral membrane of the OC. (B) An $x z$ scan of OC stained for NHE-1 (TRITC). (C) Colocalization of NHE-1 with the NaPi on basolateral membrane, especially at the clear zone area of adhesion, as indicated by pseudocolored yellow. 
glass with areas of intense staining on the plasma membrane. The OC shown in Fig. $4 B$ was positioned on a resorption pit as shown in Fig. $4 C$. Fig. 4, $D$ and $E$, shows the separate staining patterns for $\mathrm{NaPi}$ and ricin, respectively, taken from the cellular sections just above the resorption pit. Fig. $4 F$ shows the $x z$ (cross section) scan for colocalization of ricin and NaPi-2; the intensity of staining is greatest at the basolateral membrane of the polarized OC. Identical results to those in Fig. 4 were obtained using rabbit OCs cultured on glass, as shown in Fig. 5. Fig. $5 A$ shows the endosomal colocalization of ricin and the $\mathrm{NaPi}$, whereas the individual staining patterns for ricin and the $\mathrm{NaPi}$ are shown in Fig. 5, $B$ and $C$, respectively. There is both a peripheral and an intracellular distribution of the endosomal compartment in the unpolarized rabbit OC.

Distribution of NaPi in polarized OCs. To further examine the cellular distribution of the $\mathrm{NaPi}$, the distribution of another membrane transporter, the vacuolar H-ATPase, was investigated. The H-ATPase is known to distribute preferentially, but not completely, toward the ruffled membrane of the polarized OC (2). Fig. $6 A$ shows a series of basolateral (top of the cell) to apical (bottom of the cell facing substrate) scans $(4 \mu \mathrm{m})$ of a chicken OC on bone double-labeled for both NaPi-2 $\left(\mathrm{NH}_{2}\right.$-terminal antibody) and $\mathrm{H}$-ATPase (E11). There is colocalization of the two proteins only on the basolateral surface of the OC (yellow); however, as the bone surface is approached, the immunofluorescence is distinctly different for the two proteins toward the center of the cell which actually faces a resorption cavity. The staining pattern for H-ATPase (red) localized at the cell surface facing the resorption cavity, presumably the ruffled membrane, while the NaPi was limited to the basolateral membrane. The sections obtained in Fig. $6 \mathrm{~A}$ were used to generate corresponding $x z$ scans as shown in $C$. $B$ shows the dual immunofluorescent labeling for NaPi-2 and H-ATPase, at $\sim 5 \mu \mathrm{m}$ from the bone surface. The $x z$ image of the OC taken from lines in $B$ demonstrates significant colocalization for the two proteins on the basolateral membrane of the OC whereas the H-ATPase is located both on the basolateral and the ruffled membrane.

Similar to that of the chicken OC, the NaPi is also basolaterally located in the polarized rabbit OC, as shown in Fig. 7. Rabbit OCs were cultured on dentine slices before they were processed for immunostaining. A rabbit OC is shown positioned on top of a resorption pit. The basolateral location of the $\mathrm{NaPi}$ (in FITC) is readily apparent, whereas the bone surface is represented by red, as visualized by reflection microscopy.

We have shown previously that the NHE-1 isoform of the $\mathrm{Na} / \mathrm{H}$ exchanger is localized on the basolateral membrane of the polarized OC (14). Similarly, as shown in Fig. 8, the $\mathrm{NaPi}$ $(A)$ and the $\mathrm{Na} / \mathrm{H}$ exchanger $(B)$ manifest a high degree of colocalization $(C)$ only on the basolateral membrane of avian OCs. There was no apparent staining for either of the two proteins on the apical membrane facing the bone surface.

Phosphate uptake by the avian OC: stimulation by bone. Because the immunolocalization data suggest traffic of an endosomal compartment containing NaPi-2-like OC protein to the plasma membrane during organization of the $\mathrm{OC}$ in the presence of bone, we questioned whether the stimulation of $\mathrm{Pi}$ uptake by bone could be mediated by integrin-signaling mechanisms which stimulate OC polarization for resorption. We have shown previously that the stimulation of Pi uptake by bone could be attenuated by preincubating OCs with Arg-Gly-
Asp-Ser-containing peptides but not by cycloheximide or actinomycin D (10). The Arg-Gly-Asp-Ser-peptides were presumed to compete with integrin-binding sites on OCs cultured in the presence of bone. A probable candidate signaling molecule in the regulation of Pi uptake in OCs, phosphatidylinositol 3-kinase (PI 3-K) activity, has been implicated in the regulation of the basal plasma membrane glucose transporter (GLUT4). PI 3-K participates in insulin-stimulated recycling and reorganization of the intracellular transporter pools of GLUT4 both in adipose tissue and skeletal muscle $(21,22)$. Furthermore, we have shown that PI $3-\mathrm{K}$ activity in OCs is stimulated via integrin-mediated signaling (23), and its inhibition blocks bone resorption. When used at low concentrations ( $\leq 100 \mathrm{nM}$ ), wortmannin has been shown to be a relatively specific inhibitor of PI 3-K (24). Avian OC precursors allowed to differentiate in 24-well plates for $5 \mathrm{~d}$ were exposed to bone particles (+Bone, $600 \mu \mathrm{g} / \mathrm{ml}$ ) $4 \mathrm{~h}$ before the initiation of Pi uptake, in the presence of wortmannin $(100 \mathrm{nM})$ which was added to cells $30 \mathrm{~min}$ before initiation of Pi uptake. As shown in Fig. 9, there was a significant stimulation of Pi uptake in the presence of bone $(917.6 \pm 44.86 \mathrm{nmol} / \mathrm{mg}$ protein at $60 \mathrm{~min}$, $P<0.01)$ compared to that in the absence of bone $(248.3 \pm 9.33$ $\mathrm{nmol} / \mathrm{mg}$ protein). However, there was an $\sim 50 \%$ reduction in Pi uptake $(224.2 \pm 116.80 \mathrm{nmol} / \mathrm{mg}$ protein, $P<0.01)$ in cells pretreated with wortmannin compared to Pi uptake in the presence of bone alone.

Since PI 3-K regulates actin cytoskeletal reorganization during motility and attachment to bone, we also questioned whether disruption of the actin cytoskeleton by cytochalasin D (25) or the microtubular network by colchicine (26) would inhibit Pi uptake by OCs stimulated by bone. As shown in Fig. 10 , cytochalasin D $(5 \mathrm{ng} / \mathrm{ml})$ inhibited the stimulation of Pi uptake in the presence of bone $(81.3 \pm 16.81 \mu \mathrm{mol} / \mathrm{mg}$ protein at $60 \mathrm{~min}, n=9)$ by $\sim 78 \%(10.1 \pm 2.03, n=6)$. Colchicine $(100$ $\mu \mathrm{M})$, which disrupts microtubules and inhibits bone resorption

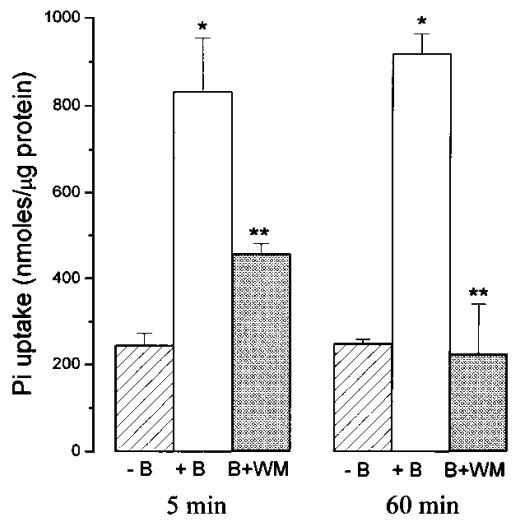

Figure 9. Effects of wortmannin on bonemediated stimulation of Pi uptake in avian OCs. Avian OC precursors were allowed to differentiate into mature OCs in culture for $5 \mathrm{~d}$. These OCs were exposed to bone particles $(+B, 600 \mu \mathrm{g} / \mathrm{ml}) 4 \mathrm{~h}$ before the initiation of $\mathrm{Pi}$ uptake, either in the absence or presence of wortmannin $(B+W M$, $100 \mathrm{nM})$. OCs which were not exposed to either bone nor wortmannin served as the untreated controls $(-B) .100 \mathrm{nM}$ wortmannin was added to cells $30 \mathrm{~min}$ before initiation of Pi uptake. Na-dependent Pi uptake was initiated with $1 \mu \mathrm{Ci} / \mathrm{ml}$ of $\mathrm{K}_{2}\left[{ }^{32} \mathrm{P}\right]-\mathrm{HPO}_{4}$ in the assay buffer (see Methods); uptake was measured at both 5 and $60 \mathrm{~min}$. Pi uptake was terminated by washing the cells twice in ice-cold PBS and then solubilizing them with $250 \mu \mathrm{l}$ of $0.2 \mathrm{~N} \mathrm{NaOH}$. The samples were processed for liquid scintillation counting and protein determination. Pi uptake is represented as means \pm SEM in $n m o l / \mu g$ protein $(n=3)$. Background uptake of ${ }^{32} \mathrm{Pi}$ in the absence of $\mathrm{Na}$ was subtracted in each condition. 


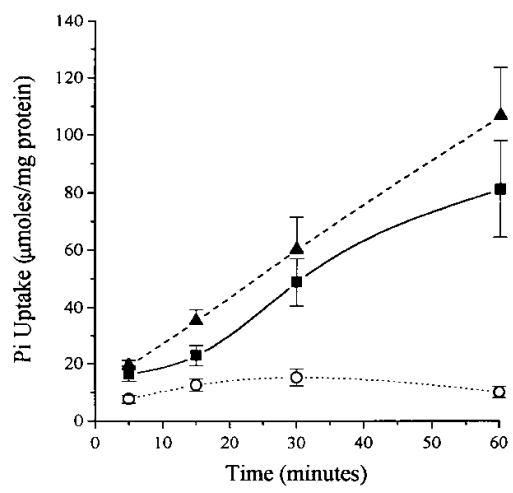

Figure 10. Effects of cytochalasin D $(5 \mathrm{ng} / \mathrm{ml})$ and colchicine (100 $\mathrm{mM}$ ) on Pi uptake by avian OCs in the presence of bone. Avian OC precursors were allowed to differentiate into mature OCs in culture for $5 \mathrm{~d}$. These OCs were exposed to bone particles $(600 \mu \mathrm{g} / \mathrm{ml}$, 口), either in the presence of cytochalasin D $(\bigcirc)$ or colchicine $(\boldsymbol{\Delta})$ $4 \mathrm{~h}$ before the initiation of the Pi uptake assay. Na-dependent Pi uptake was initiated with $1 \mu \mathrm{Ci} / \mathrm{ml}$ of $\mathrm{K}_{2}\left[{ }^{32} \mathrm{P}\right] \mathrm{HPO}_{4}$ in the assay buffer for $5,15,30$, and $60 \mathrm{~min}$. Pi uptake was terminated by washing the cells twice in ice-cold PBS and then solubilizing them with $250 \mu \mathrm{l}$ of $0.2 \mathrm{~N} \mathrm{NaOH}$. These samples were processed for liquid scintillation counting and protein determination. Pi uptake is represented as means \pm SEM in $\mu \mathrm{mol} / \mathrm{mg}$ protein ( $n=6-9$ determinations). Background uptake of ${ }^{32} \mathrm{Pi}$ in the absence of $\mathrm{Na}$ was subtracted in each experimental condition.

(27), had no inhibitory effect on Pi uptake in the presence of bone $(106.7 \pm 16.9 \mu \mathrm{mol} / \mathrm{mg}$ protein, $n=6)$.

The effect of PFA on OC Pi transport. Since exposure to bone markedly increased Pi uptake, we questioned whether PFA, a specific inhibitor of the renal NaPi (28), could also inhibit Pi uptake by the OC. PFA is known to exert its inhibitory effect by binding to the same locus where both $\mathrm{Pi}$ and $\mathrm{Na}^{+}$ form a ternary complex with the $\mathrm{NaPi}$. Pi uptake was initiated after a 4-h exposure to bone particles $(600 \mu \mathrm{g} / \mathrm{ml})$ in the presence and absence of PFA (5 mM). As shown in Fig. 11, PFA treatment produced $\sim 70 \%$ inhibition of Pi uptake at $60 \mathrm{~min}$ $(13.8 \pm 2.61 \mu \mathrm{mol} / \mathrm{mg}$ protein, $n=3)$ compared to that in the presence of bone alone $(81.3 \pm 16.81 \mu \mathrm{mol} / \mathrm{mg}$ protein, $n=9$, $P<0.001)$. To provide an indication of the specificity of PFA on Pi transport in the bone, we examined the effects of PFA on Na-dependent Pi uptake in osteoblast-like cells. We have been unable to find evidence for an NaPi-2-like protein in osteoblasts, either by immunologic cross-reactivity or by detection of message using PCR. We have observed in osteoblast-like UMR-106-01 cells that although the presence of bone increased Na-dependent Pi uptake PFA did not inhibit Pi transport (data not shown). Since the NaPi proteins are the PFA binding proteins $(28,29)$, the effect of PFA on OC Pi transport is additional evidence of an NaPi-like protein in the OC.

We next determined whether the inhibition of NaPi activity by both PFA and wortmannin was accompanied by a corresponding loss of its expression at the cell surface. We performed two separate sets of experiments which comprised both immunolocalization and cell surface biotinylation of the $\mathrm{NaPi}$ in the OC. For the biotinylation studies, avian OCs were cultured in the presence of bone particles for $48 \mathrm{~h}$ in the presence of either $5 \mathrm{mM}$ PFA or $100 \mathrm{nM}$ wortmannin (1-h pretreatment). Untreated OCs cultured in the presence of bone particles served as the controls. As shown in Fig. $12 \mathrm{~A}$, the levels of the biotinylated $\mathrm{NaPi}$ are not affected greatly by treatment with PFA (lane 2) compared to that in controls (lane 1). However, when OCs were pretreated with wortmannin (100

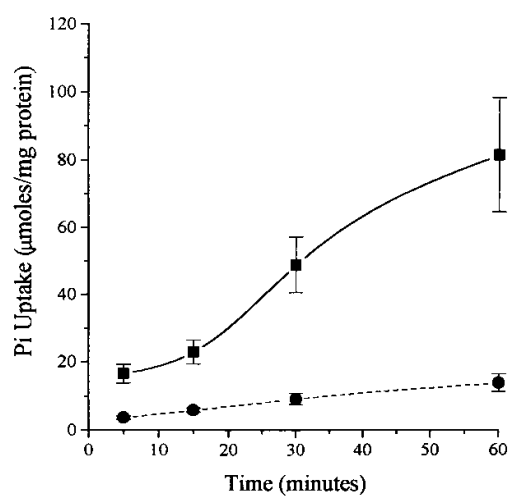

Figure 11. Time course of Pi uptake by avian OCs: effects of PFA in the presence of bone. Avian OC precursors were allowed to differentiate into mature OCs in culture for $5 \mathrm{~d}$. These OCs were exposed to either bone particles alone $(600 \mu \mathrm{g} / \mathrm{ml}, \mathbf{\square})$ or a combination of bone and PFA ( $5 \mathrm{mM}, \bullet), 4 \mathrm{~h}$ before the initiation of the Pi uptake assay. Nadependent Pi uptake was initiated with $1 \mu \mathrm{Ci} / \mathrm{ml}$ of $\mathrm{K}_{2}\left[{ }^{32} \mathrm{P}\right] \mathrm{HPO}_{4}$ in the assay buffer for 5, 15, 30, and $60 \mathrm{~min}$. Pi uptake was terminated by washing the cells twice in ice-cold PBS and then solubilizing them with $250 \mu \mathrm{l}$ of $0.2 \mathrm{~N} \mathrm{NaOH}$. These samples were processed for liquid scintillation counting and protein determination. Pi uptake is represented as means \pm SEM in $\mu \mathrm{mol} / \mathrm{mg}$ protein $(n=3)$.

$\mathrm{nM}$ ) for $1 \mathrm{~h}$ before the addition of bone particles, there was a dramatic reduction in the levels of the $\mathrm{NaPi}$ at the cell surface (lane 3). For the immunolocalization studies of the NaPi under corresponding conditions, avian OCs were cultured on bone wafers for $3 \mathrm{~d}$, after being pretreated for 1-2 h with $5 \mathrm{mM}$ PFA or $100 \mathrm{nM}$ wortmannin. Fig. $12, B-D$, shows the corresponding confocal immunofluorescent studies for both the untreated (control), PFA-, and wortmannin-treated OCs. As shown in $B$, there was a significant level of $\mathrm{NaPi}$ expression at the periphery of the untreated $\mathrm{OC}$ on bone with little intracellular staining. However, when the cells were treated with PFA $(5 \mathrm{mM})$, the intensity of the intracellular staining for the $\mathrm{NaPi}$ was greatly increased $(C)$, although a decrease in cell surface staining is not readily apparent, as suggested by the biotinylation studies. In addition, as shown in $D$, in OCs pretreated with 100 $\mathrm{nM}$ wortmannin, there was an even greater increase in the diffuse intracellular staining than seen with PFA. Therefore, we obtained the corresponding $x z$ scans for the control $(B)$ and the wortmannin-treated group of OCs $(D)$. As shown in $E$, the staining for the $\mathrm{NaPi}$ is very close to the basolateral domain of the OC; the cell periphery is outlined in free hand. In contrast, the staining pattern for $\mathrm{NaPi}$ in the wortmannin-treated $\mathrm{OC}$ is distinctly intracellular with very little basolateral staining.

The effect of NaPi transport inhibition on bone resorption. We had initially hypothesized that the NaPi is recruited to the plasma membrane for Pi uptake during bone resorption in order to provide the Pi for energy metabolism (30). We next asked the question whether inhibition of Pi uptake could attenuate the capacity of the OC to resorb bone. Fig. 13 shows the results of a quantitative bone resorption assay to assess the effects of PFA on bone resorption by OCs, represented as cpm $\left[{ }^{3} \mathrm{H}\right]$ proline/mg protein (percentage of control). OC precursors were allowed to differentiate in the presence of $\left[{ }^{3} \mathrm{H}\right]$ prolinelabeled bone $\left(2.5 \times 10^{5} \mathrm{cpm} /\right.$ well $)$ in 24 -well plates. On day 3 , varying doses of 1,2 , and $5 \mathrm{mM}$ PFA were added to each well. On day $5,1.0 \mathrm{ml}$ of the culture media was sampled for $\left[{ }^{3} \mathrm{H}\right]$ proline release (cpm $\left[{ }^{3} \mathrm{H}\right]$ proline/mg protein). On day 6 , the medium was sampled again, then the cells were lysed with $0.2 \mathrm{~N}$ $\mathrm{NaOH}$ to assay for protein content. The dose-dependent inhibitory effects of PFA on bone resorption (expressed as per- 

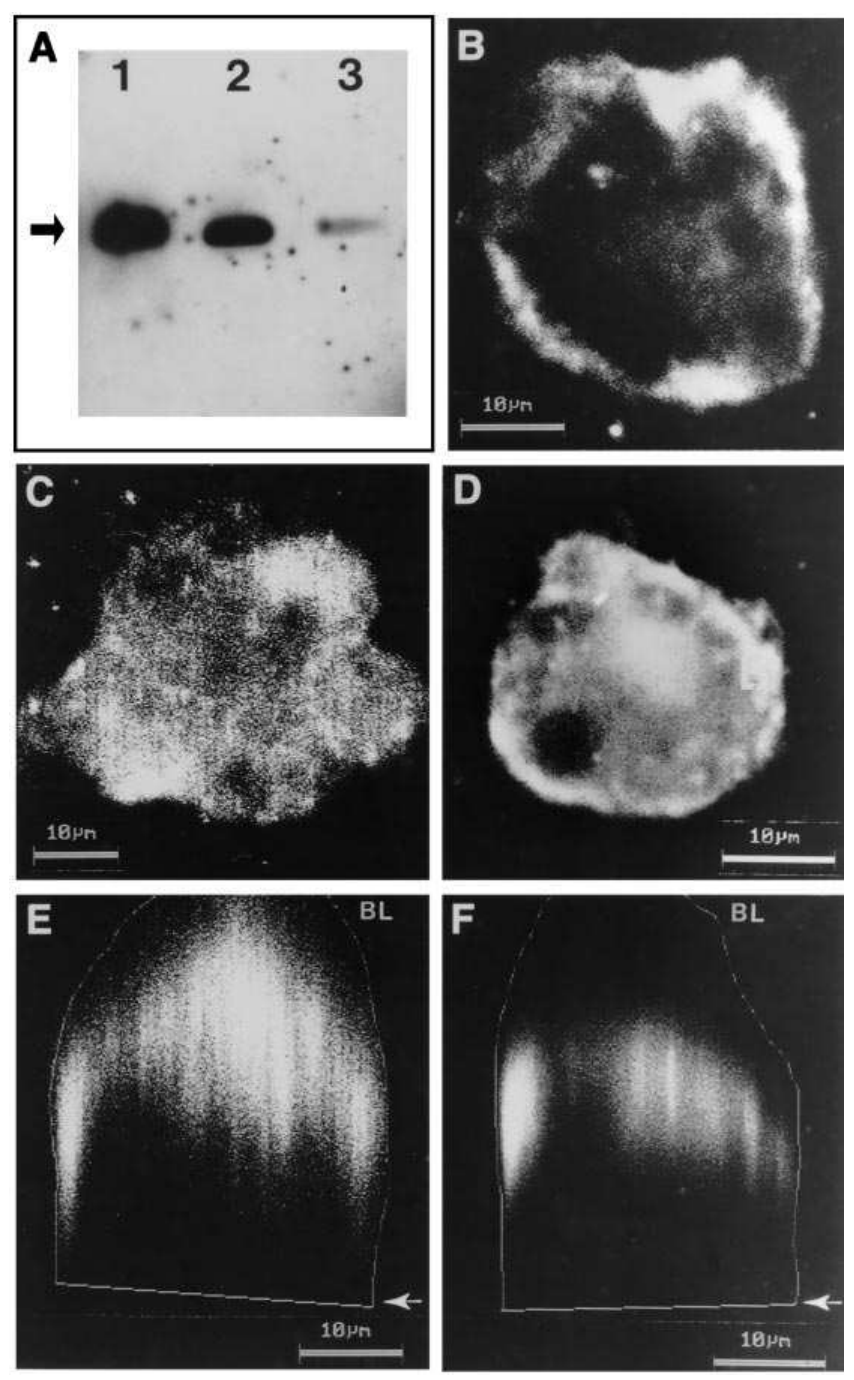

Figure 12. Effects of PFA and wortmannin on cell surface expression of NaPi. (A) Biotinylation of NaPi. Avian OCs were cultured in 24well plates in the absence or presence of bone chips. Biotinylation was performed using sulfo-NHS-biotin $(0.5 \mathrm{mg} / \mathrm{ml})$ under the following conditions: + bone (lane 1$)$, +PFA + bone (lane 2), and + wortmannin + bone (lane 3). ( $B-D)$ Immunolocalization of NaPi. Avian OCs were cultured on dentine slices and were treated with either $5 \mathrm{mM}$ PFA $(C)$ or $100 \mathrm{nM}$ wortmannin $(D)$. Untreated OCs served as controls $(B) . E$ and $F$ show the corresponding $x z$ scans for the control OC on bone $(B)$ and the wortmannin-treated OC $(D)$. The cell periphery of the corresponding OCs were sketched free-hand as they sat on the bone surface.

centage of control) were apparent at $1 \mathrm{mM}(61.3 \pm 5.10, n=$ 24), $2 \mathrm{mM}(48.2 \pm 2.90, n=24)$, and $5 \mathrm{mM}$ PFA (40.2 \pm 2.84 , $n=24$ ) compared to the control (untreated) group of OCs $(100.0 \pm 9.91, n=24)$. We have extended these findings of inhibition of bone resorption by PFA to a mouse OC-stromal cell coculture system (13). Similar to our observations in the avian OC, there was an $\sim 50 \%$ reduction in bone resorption, as shown in Fig. 14.

Our observations on the PFA-mediated inhibition of bone resorption by OCs using the release of $\left[{ }^{3} \mathrm{H}\right]$ proline were corroborated using the pit assay. Avian OCs were cultured on os-

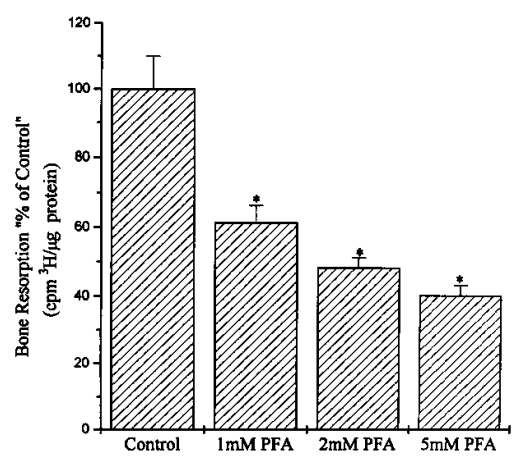

Figure 13. Dose-dependent inhibition of OCmediated bone resorption by PFA: release of ${ }^{3} \mathrm{H}$-prelabeled proline. Avian OC precursors were allowed to differentiate into mature OCs in culture in the presence of bone chips (600 $\mu \mathrm{g} / \mathrm{ml})$ for $5 \mathrm{~d}$ in 24 -well plates. On day $1,{ }^{3} \mathrm{H}$ bone chips $\left(2.5 \times 10^{5}\right.$ $\mathrm{cpm} /$ well) were added.

On day 3, PFA was added at various concentrations of 1,2 , and $5 \mathrm{mM}$ to each well. Untreated cultures served as the controls. $1.0 \mathrm{ml}$ of the culture media was sampled from each of the different treatment groups on both days 4 and 5 to assess the amount of ${ }^{3} \mathrm{H}$-bone being resorbed. After the last sampling period, the cells were lysed with $0.2 \mathrm{~N} \mathrm{NaOH}$ and assayed for protein content. Bone resorption is represented as percentage of control ( $\mathrm{cpm}^{3} \mathrm{H} / \mathrm{mg}$ protein).

teologic discs (Millenium Biologix Inc.), which are quartz plates coated with a $1-\mu \mathrm{m}$-thick film of calcium phosphate. This system provides a very reliable estimation of bone resorption (17). As shown in Fig. $15 A$, there was extensive dissolution of the calcium phosphate film by untreated control OCs, manifested by dark spots on the osteologic disc. In contrast, there was a dramatic reduction in the extent of bone resorption by OCs treated with $1,2.5$, and 5 mM PFA (Fig. 15, $B-D$ ). The higher magnification $(\times 20)$ images in Fig. $15, E-H$ show the corresponding resorption pits: the extensive resorption by the untreated control group of OCs is apparent $(E)$ whereas minimal resorption is seen in the PFA-treated groups $(F-H)$. The re-

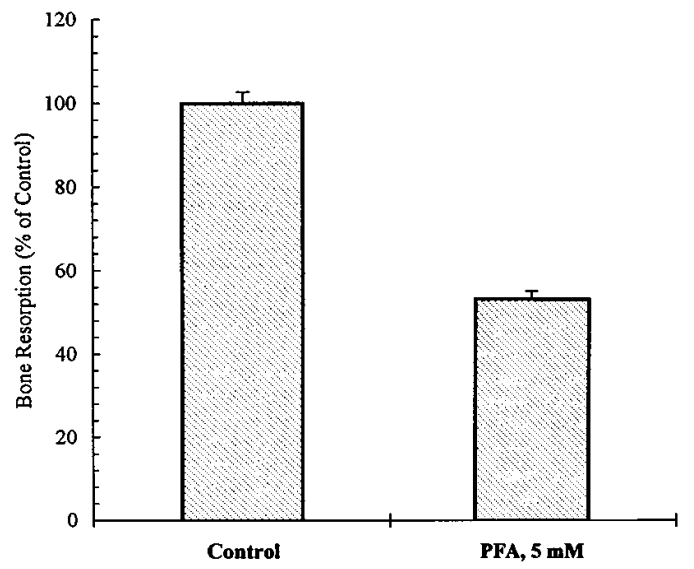

Figure 14. Inhibition of mouse OC-mediated bone resorption by PFA: release of ${ }^{3} \mathrm{H}$-prelabeled proline. Mouse OCs were cultured in the presence of bone chips $(600 \mu \mathrm{g} / \mathrm{ml})$ for $5 \mathrm{~d}$ in 24 -well plates. On day $1,{ }^{3} \mathrm{H}$-bone chips $\left(2.5 \times 10^{5} \mathrm{cpm} /\right.$ well $)$ were added. On day 3 , PFA was added at a concentration of $5 \mathrm{mM}$ to each well. Untreated cultures served as the controls. $1.0 \mathrm{ml}$ of the culture media was sampled from both the control and treated groups on both days 4 and 5 to assess the amount of ${ }^{3} \mathrm{H}$-bone being resorbed. After the last sampling period, the cells were lysed with $0.2 \mathrm{~N} \mathrm{NaOH}$ and assayed for protein content. Bone resorption is represented by $\mathrm{cpm}^{3} \mathrm{H} / \mathrm{mg}$ protein (percentage of control). 

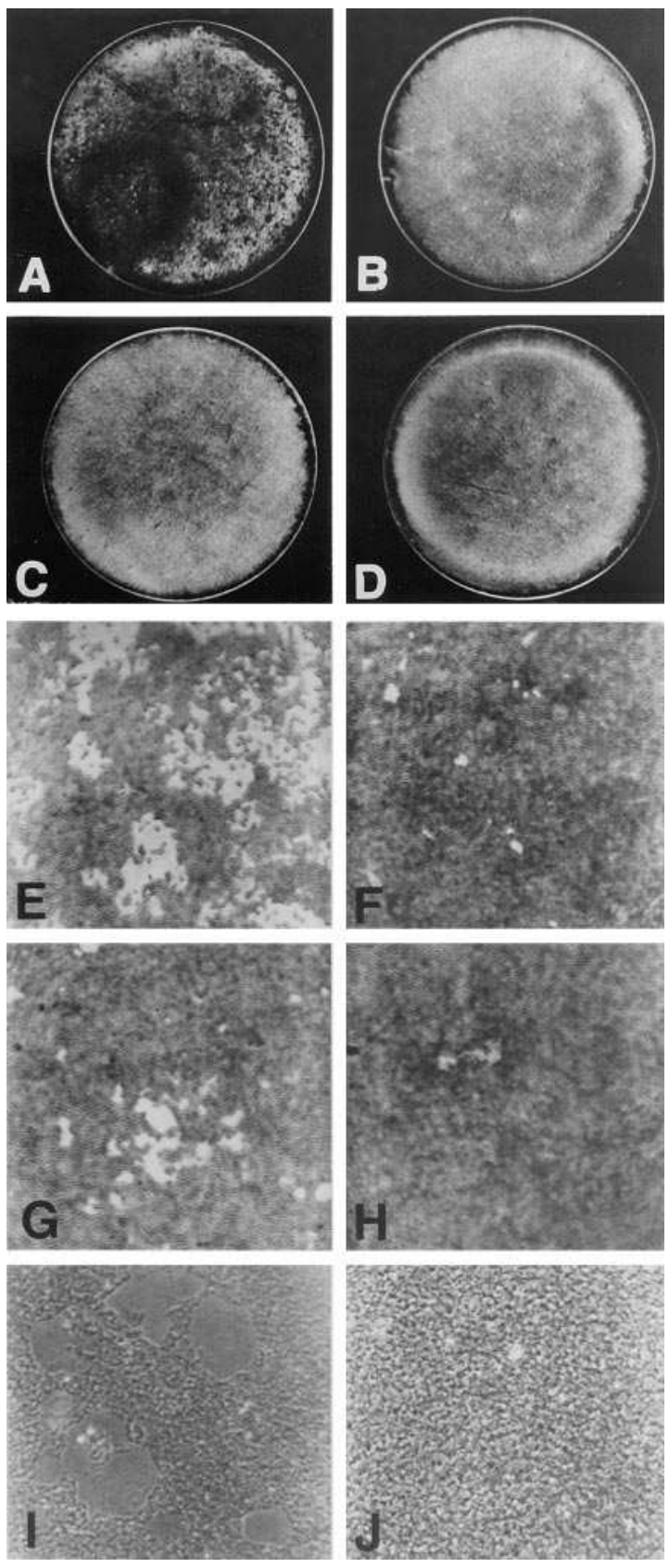

Figure 15. Dose-dependent inhibition of OC-mediated bone resorption by PFA: pit assay. Avian OCs were plated on osteologic discs (coated with a $1-\mu \mathrm{m}$-thick calcium phosphate film). These were then cultured for $5 \mathrm{~d}$ in 24-well plates. $(A)$ Untreated cultures served as the controls. $(B-D)$ PFA was added at various concentrations of $1,2.5$, and $5 \mathrm{mM}$ to each well. $(E-H) \times 20$ of resorption pits in control, 1 , 2.5 , and $5 \mathrm{mM}$ PFA-treated cultures. $(I-J) \times 40$ of resorption pits in control and $5 \mathrm{mM}$ PFA-treated OCs, respectively.

sorption pits made by the control group of OCs on the osteologic discs can be seen in more detail in a $\times 40$ image $(I)$, in contrast to the total absence of resorptive activity in the PFAtreated OC $(J)$. Therefore, our data suggest that avian OCmediated bone resorption is acutely sensitive to PFA, with an apparent threshold of $\sim 1 \mathrm{mM}$.

We next proposed to determine whether PFA was able to inhibit oxidative metabolism in OCs actively engaged in bone

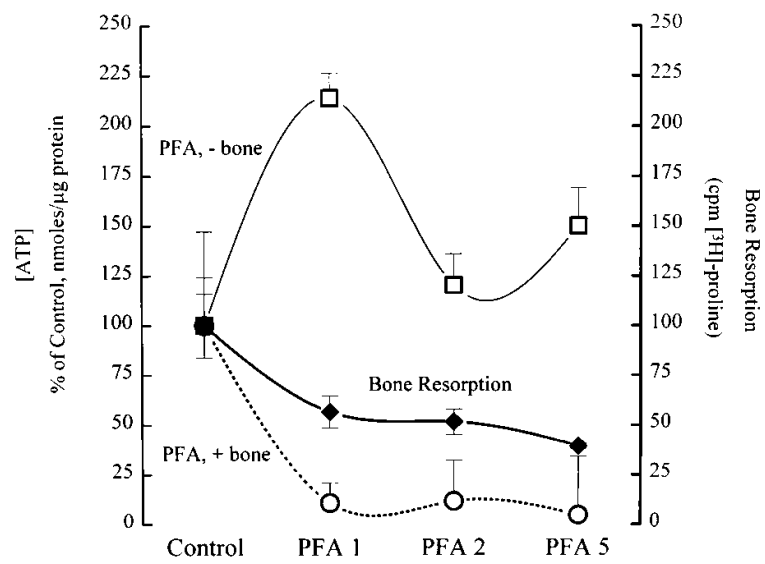

Figure 16. Effects of PFA on OC-mediated bone resorption and ATP content in avian OCs. Avian OC precursors were allowed to differentiate into mature OCs in culture in 24 -well plates. On day 4 in culture, $\left[{ }^{3} \mathrm{H}\right]$ proline-labeled bone chips $\left(2.5 \times 10^{5} \mathrm{cpm} /\right.$ well $)$ were added to two of the cultures. PFA was added at various concentrations of 1,2 , and $5 \mathrm{mM}$ to each well. Untreated cultures served as the controls $(100 \%)$. ATP content was assayed either in the absence $(\square)$ or presence of bone $(\bigcirc)$. Bone resorption (represented as percentage of control, $(\diamond)$ was assayed by the OC-mediated release of $\left[{ }^{3} \mathrm{H}\right]$ proline into the media, as shown on the right axis.

resorption. Our working hypothesis was based upon the premise that limitations of substrate availability in the form of Pi would impair oxidative metabolism (30) in OCs actively resorbing bone. For these experiments, chicken OC precursors were allowed to differentiate (into mature multinucleated OCs) over $4 \mathrm{~d}$ in 24-well plates. Three parallel cultures were assayed for the effects of varying doses of PFA $(1,2$, and $5 \mathrm{mM})$ on ATP content in OCs and bone resorption. After $48 \mathrm{~h}$ in the absence and presence of bone $\left(\left[{ }^{3} \mathrm{H}\right]\right.$ proline-labeled bone particles), an ATP assay was performed on the cultures. As shown in Fig. 16, the addition of PFA to OCs actively resorbing bone led to a dose-dependent decline in bone resorption $(39.6 \pm 1.25 \%$ of maximal at $5 \mathrm{mM}, n=3)$, expressed as percentage of control $(100.0 \pm 16.10, n=3)$. As shown in Fig. 15, there was no apparent effect from varying doses of PFA on ATP content ([ATP]) in OCs cultured in the absence of bone (PFA, - bone). The ATP content was unchanged from $100 \pm 24.33 \%$ (control) to $150 \pm 19.17 \%$ ( 5 mM PFA). This indicated that the OCs were not adversely affected by chronic exposure to PFA (over $48 \mathrm{~h}$ ) and that a possible lack of cell viability was not a contributing factor in the inhibition of bone resorption by PFA. However, when the OCs were exposed to PFA in the presence of bone, there was a significant reduction of cell ATP content from $100 \pm 47.22 \%(n=3)$ in control/untreated OCs to $\sim 5 \%(n=3)$, maximal at 5 mM PFA.

\section{Discussion}

In this study, we demonstrate that antibodies directed either toward the $\mathrm{COOH}$ - and/or the $\mathrm{NH}_{2}$-terminal portions of the renal NaPi- 2 cross-react with an $\sim 95-\mathrm{kD}$ protein in both avian and rabbit OCs. By PCR, we show the presence of an NaPi-6related cDNA sequence in a rabbit OC library. We also demonstrate that a chemical agent, PFA, which binds to and inhibits the renal NaPi proteins, inhibits OC but not osteoblast $\mathrm{Pi}$ 
transport in the presence of bone. PFA, however, does not alter expression levels of the $\mathrm{NaPi}$ on the cell surface, as judged from our biotinylation studies. This result is in agreement with the possibility that PFA is a competitive inhibitor of the transport protein, as studies in the kidney indicate (28). The first conclusion of this study is that the OC $95-\mathrm{kD}$ protein is related to the renal NaPi-2 to -6 cotransporters. The basis for the larger than expected apparent molecular size is unknown, but one possibility is that the $\mathrm{OC} \mathrm{NaPi}$ is an alternate splice variant of the renal NaPi family. Glycosylation does not appear to be the basis for the difference in apparent molecular size as the OC $95-\mathrm{kD}$ protein is insensitive to endoglycosidases, in contrast to that reported previously for NaPi-2 (19).

Immunolocalization studies of the $\mathrm{OC}$ using the NaPi-2 $\left(\mathrm{NH}_{2}\right.$ and $\mathrm{COOH}$ termini) antibodies reveal the presences of a cross-reactive protein in discrete vesicles and unpolarized OC cultured on glass which redistributed toward the periphery of cells exposed to bone matrix. Na-dependent Pi transport in the OC was stimulated in the presence of bone, associated with the stimulation of the $\mathrm{NaPi}$-like protein expression in the plasma membrane. Vesicular cytoplasmic immunostaining for the $\mathrm{NaPi}$ in unpolarized OCs suggests the presence of an intracellular pool of NaPi $(31,32)$. Immunofluorescence data demonstrating colocalization of the $\mathrm{NaPi}$ and ricin, a general marker for endocytosis and recycling of internalized membrane proteins (20), further support the endosomal nature of the vesicular pools containing the $\mathrm{NaPi}$. Upon attachment to bone, dual immunofluorescence microscopy revealed that the $\mathrm{NaPi}$ and NHE-1 localize to the basolateral domain of the polarized OC, in contrast to the vacuolar H-ATPase which sorts to the ruffled membrane facing the bone surface. Therefore, we have demonstrated that bone stimulates insertion or targeting of the $\mathrm{NaPi}$ to the basolateral membrane. The expression of a transport protein for uptake of $\mathrm{Pi}$ in the basolateral membrane of the OC may seem surprising. However, it is known that the $\mathrm{NaPi}$ transports monobasic $\mathrm{H}_{2} \mathrm{PO}_{4}^{-}$less effectively than $\mathrm{HPO}_{4}^{=}$ in renal and intestinal epithelia (33). Therefore, the ambient $\mathrm{pH}$ of the resorption space would render an NaPi-2-like protein comparatively inefficient, since protons compete with $\mathrm{Na}^{+}$ for binding to the external $\mathrm{Na}^{+}$interaction site. Thus, the basolaterally located protein would be exposed to an ambient $\mathrm{pH}$ closer to its maximum efficiency.

The mechanisms accounting for movement of the NaPicontaining vesicular compartment to the plasma membrane remain to be investigated. However, our observations demonstrating inhibition of both bone-stimulated Pi uptake and surface expression of the NaPi by wortmannin suggest that PI 3-K may be linked to regulation of Pi transport in the OC. It is possible that wortmannin may inhibit general vesicular traffic or inhibit other molecule/components which are critical to Pi uptake. Our preliminary results are reminiscent of the involvement of PI 3-K in the insulin-induced stimulation of GLUT4containing vesicles translocating to the plasma membrane in adipose tissue and skeletal muscle in response to insulin (22). Our biotinylation studies suggest that the cell surface expression levels of the $\mathrm{NaPi}$ are reduced in the presence of wortmannin. Furthermore, cytochalasin D, which promotes actin disassembly, inhibited the stimulation of $\mathrm{NaPi}$ in the presence of bone, linking previous studies of the OC actin cytoskeleton and PI 3-K (23) to bone-stimulated traffic of the NaPi-like transporter. Previous studies have shown that cytochalasin D inhibits formation of the ruffled border and consequently bone resorption (25). However, the microtubule-disrupting agent colchicine had no effect on OC Pi uptake although it, too, has been reported to disrupt the OC ruffled border $(26,27)$. We have corroborated the latter observations of inhibition of bone resorption by both cytochalasin $\mathrm{D}$ and colchicine. When the OC becomes polarized in the presence of bone, it forms three distinct membranes: a ruffled membrane, a sealing zone facing the bone substrate, and a basolateral membrane (1). Our data suggest that during this polarization, there may be an associated redistribution of $\mathrm{NaPi}$ to the basolateral membrane of the OC.

The vesicular cytoplasmic immunostaining for the NaPi in unpolarized chicken OCs suggests the presence of an intracellular pool of $\mathrm{NaPis}(31,32)$. Our immunofluorescence data demonstrate that discrete vesicles stain for the NaPi and for TRITCconjugated ricin. Since ricin is used as a general marker for endocytosis and recycling of apically internalized membrane proteins (20), our double-label immunofluorescence demonstrates a high degree of colocalization of the OC NaPi-2 protein and ricin in these endosomal pools.

Our dual immunofluorescence microscopy for the $\mathrm{NaPi}$, the $\mathrm{H}$-ATPase, and the $\mathrm{Na} / \mathrm{H}$ exchanger attest to the specificity of the basolateral location of the transporter. The expression of a transport protein for uptake of $\mathrm{Pi}$ in the basolateral membrane of the $\mathrm{OC}$ may seem surprising. It is known that the $\mathrm{NaPi}$ transports monobasic $\mathrm{H}_{2} \mathrm{PO}_{4}^{-}$less effectively than $\mathrm{HPO}_{4}^{=}$ in renal and intestinal epithelia (33). Therefore, the ambient $\mathrm{pH}$ of the resorption space would render an NaPi-2-like protein comparatively inefficient, since protons compete with $\mathrm{Na}^{+}$ for binding to the external $\mathrm{Na}^{2+}$ interaction site. However, in contrast to the renal and intestinal epithelia, Na-dependent $\mathrm{Pi}$ uptake is higher at $\mathrm{pH} 6.5$ compared to $\mathrm{pH} 7.4$ in $\mathrm{ROS} \mathrm{17/2.8}$ osteoblast-like cells $(34,35)$, which suggested that the monobasic form of $\mathrm{Pi}, \mathrm{H}_{2} \mathrm{PO}_{4}^{-}$, was the preferred substrate. The stimulatory effect of low $\mathrm{pH}$ on $\mathrm{Pi}$ uptake in osteoblasts is characteristic of the type III family of NaPis shown to be present in the osteoblast (9). We have yet to determine the preferred substrate for the Na-dependent Pi uptake in OCs.

PFA was originally discovered to be a specific, competitive and reversible inhibitor of NaPi-transport across the brushborder membrane of the renal proximal tubule (28). Our data on inhibition of Pi uptake by PFA $(\sim 80 \%$ at $5 \mathrm{mM})$ in OCs are compatible with previous studies in the kidney. The observation that PFA inhibits bone resorption raises several interesting possibilities. Native human OCs have a high capacity to generate ATP via the Krebs cycle, and this is increased during the process of bone resorption (3). OCs are also biosynthetic cells (1) but when they encounter bone or initiate resorption, the normal levels of biosynthesis requiring de novo RNA production are diminished, partly due to the generation of free radicals (36). OCs use high rates of $\beta$-fatty acid oxidation to support generation of Krebs cycle intermediates (37), and limitations of a substrate such as Pi could limit ATP generation $(7,8)$. Our functional and immunochemical results show that in the absence of bone, the OC's NaPi are not expressed at the surface to any great extent. Only when the OC becomes polarized does its capacity to transport Pi increase. Therefore, the OC may become limited in Pi availability (resulting in ATP depletion) in the presence of PFA. We have corroborated the latter hypothesis by testing the effects of PFA on ATP content in OCs in the absence and presence of bone. In the absence of bone, the energy requirements of OCs are minimal since they are not engaged in bone resorption. In this quiescent situation, 
the $\mathrm{NaPi}$ is not expressed to any significant degree on the plasma membrane. The lack of effect of PFA on OC ATP content demonstrates that the drug was not toxic to the OCs.

The increased surface expression and activity of the $\mathrm{NaPi}$ in the polarized bone-resorbing $\mathrm{OC}$ would serve to drive $\mathrm{Pi}$ uptake from the interstitial fluid after its release from the dissolution of bone, in order to maintain its energy requirements. Therefore, in summary, OCs cultured in the presence of bone particles exhibit an increase in the level of the NaPi in both the microsomal and plasma membrane fractions. This upregulation may reflect the acute increases in Pi uptake observed in the presence of bone. Inhibition of Pi uptake in the presence of bone blocks bone resorption, demonstrating the importance of phosphate transport in the process.

\section{Acknowledgments}

We acknowledge the expert help of John Freeman, Ph.D., at the Pediatric Research Institute, St. Louis University Medical Center, in generating the laser scanning confocal images.

This work was supported by the Barnes-Jewish Hospital Research Foundation Grant (A. Gupta) and National Institutes of Health grants DK09976, AR41677, AR39561, and AR32087 (K.A. Hruska).

\section{References}

1. Baron, R., J.H. Ravesloot, L. Neff, M. Chakraborty, D. Chatterjee, A. Lomri, and W. Horne. 1993. Cellular and molecular biology of the osteoclast. In Cellular and Molecular Biology of Bone. M. Noda, editor. Academic Press Inc., New York. 445-495.

2. Blair, H.C., S.L. Teitelbaum, R. Ghiselli, and S. Gluck. 1989. Osteoclastic bone resorption by a polarized vacuolar proton pump. Nature (Lond.). 245:855857.

3. Bradbeer, J.N., M. Gowen, and R.A. Dodds. 1992. In situ demonstration of the increased ability of human osteoclasts to generate ATP during bone resorption. J. Bone Miner. Res. 7:S312.

4. Magagnin, S., A. Werner, D. Markovich, V. Sorribas, G. Stange, J. Biber, and H. Murer. 1993. Expression cloning of human and rat renal cortex $\mathrm{Na} / \mathrm{P}_{\mathrm{i}}$ cotransport. Proc. Natl. Acad. Sci. USA. 90:5979-5983.

5. Verri, T., D. Markovich, C. Perego, F. Norbis, G. Stange, V. Sorribas, J. Biber, and H. Murer. 1995. Cloning of a rabbit renal NaPi cotransporter which is regulated by dietary phosphate. Am. J. Physiol. 268:F626-F633.

6. Werner, A., M.L. Moore, N. Mantei, J. Biber, G. Semenza, and H. Murer. 1991. Cloning and expression of cDNA for a Na/Pi cotransport system of kidney cortex. Proc. Natl. Acad. Sci. USA. 88:9608-9612.

7. Werner, A., H. Murer, and R.K.H. Kinne. 1994. Cloning and expression of a renal NaPi cotransport system from flounder. Am. J. Physiol. 267:F311F317.

8. Custer, M., M. Lötscher, J. Biber, H. Murer, and B. Kaissling. 1994. Expression of NaPi cotransport in rat kidney: localization by RT-PCR and immunohistochemistry. Am. J. Physiol. 266:F767-F774.

9. Kavanaugh, M.P., and D. Kabat. 1996. Identification and characterization of a widely expressed phosphate transporter/retrovirus receptor family. Kidney Int. 49:959-963.

10. Gupta, A., A. Miyauchi, A. Fujimori, and K.A. Hruska. 1996. Phosphate transport in osteoclasts: a functional and immunochemical characterization. Kidney Int. 49:968-974.

11. Alvarez, J.I., S.L. Teitelbaum, H.D. Blair, E.M. Greenfield, N.A. Athanasou, and F.P. Ross. 1991. Generation of avian cells resembling osteoclasts from mononuclear phagocytes. Endocrinology. 128:2324-2325.

12. Tezuka, K., Y. Tezuka, A. Maejima, T. Sato, K. Nemoto, H. Kamioka, Y. Hakeda, and M. Kumegawa. 1994. Molecular cloning of a possible cysteine proteinase predominantly expressed in osteoclasts. J. Biol. Chem. 269:11061109.
13. Shioi, A., F.P. Ross, and S.L. Teitelbaum. 1994. Enrichment of generated murine osteoclasts. Calcif. Tissue Int. 55:387-394.

14. Gupta, A., J.C. Edwards, and K.A. Hruska. 1996. Cellular distribution and regulation of NHE-1 isoform of the $\mathrm{Na}-\mathrm{H}$ exchanger in the avian osteoclast. Bone (N.Y.). 18:87-95.

15. Sambrook, J., E.F. Fritsch, and T. Maniatis. 1989. Molecular Cloning: A Laboratory Manual, 2nd Ed. Cold Spring Harbor Laboratory Press, Cold Spring Harbor, NY.

16. Sanger, F.A., S. Nicklen, and A.R. Coulson. 1977. DNA sequencing with chain-terminating inhibitors. Proc. Natl. Acad. Sci. USA. 74:5463-5467.

17. Nakamura, I., N. Takahashi, T. Sasaki, E. Jimi, T. Kurokawa, and T. Suda. 1996. Chemical and physical properties of the extracellular matrix are required for the actin ring formation in osteoclasts. J. Bone Miner. Res. 11:18731879.

18. Adams, H. 1963. Methods in Enzymatic Analysis. H.U. Bergmeyer, editor. Academic Press Inc., NY. 539-543.

19. Hayes, G., A. Busch, M. Lotscher, S. Waldegger, F. Lang, F. Verrey, J. Biber, and H. Murer. 1984. Role of N-linked glycosylation in rat renal Na/Picotransport. J. Biol. Chem. 269:24143-24149.

20. van Deurs, B., S.H. Hansen, O.W. Petersen, E.L. Melby, and K. Sandvig. 1990. Endocytosis, intracellular transport and transcytosis of the toxic protein ricin by a polarized epithelium. Eur. J. Cell Biol. 51:96-109.

21. Cheatham, B., C. Vlahos, L. Cheatham, L. Wang, J. Blenis, and C.R Kahn. 1994. Phosphatidylinositol 3-kinase activation is required for insulin stimulation of pp70 S6 kinase, DNA synthesis, and glucose transporter translocation. Mol. Cell. Biol. 14:4902-4911.

22. Okada, T., L. Sakuma, Y. Fukui, O. Hazeki, and M. Ui. 1994. Essential role of phosphatidylinositol 3-kinase in insulin-induced glucose transport and antilipolysis in rat adipocytes. J. Biol. Chem. 269:3563-3567.

23. Hruska, K.A., F. Rolnick, M. Huskey, U. Alvarez, and D.A. Cheresh. 1995. Engagement of the osteoclast integrin $\alpha_{v} \beta_{3}$ by osteopontin stimulates phosphatidylinositol 3-hydroxyl kinase activity. Endocrinology. 136:2984-2992.

24. Thelen, M., M.P. Wymann, and H. Langen. 1994. Wortmannin binds specifically to 1-phosphatidylinositol 3-kinase while inhibiting guanine nucleotide-binding protein-coupled receptor signaling in neutrophil leukocytes. Proc. Natl. Acad. Sci. USA. 91:4960-4964.

25. Sasaki, T., K. Debari, and N. Udagawa. 1993. Cytochalasin D reduces osteoclastic bone resorption by inhibiting development of ruffled border-clear zone complex. Calcif. Tissue Int. 53:217-221.

26. Borisy, G.G., and E.W. Taylor. 1967. The mechanism of action of colchicine. Binding of colchicine- ${ }^{3} \mathrm{H}$ to cellular protein. J. Cell Biol. 34:525-533.

27. Rowe, D.J., and E. Hausmann. 1980. The effects of calcitonin and colchicine on the cellular response to diphosphonate. Br. J. Exp. Pathol. 61:303309.

28. Yusufi, A.N.K., M. Szczepanska-Konkel, S.A. Kempson, J.A. McAteer, and T.P. Dousa. 1986. Inhibition of human renal epithelial $\mathrm{Na}^{+} / \mathrm{Pi}$ cotransport by phosphonoformic acid. Biochem. Biophys. Res. Commun. 139:679-686.

29. Szczepanska-Konkel, M., A.N.K. Yusufi, M. VanScoy, S.K. Webster, and T.P. Dousa. 1986. Interactions of $\left[{ }^{14} \mathrm{C}\right]$ phosphonoformic acid with renal cortical brush-border membranes. J. Biol. Chem. 261:6375-6383.

30. Brazy, P.C., L.J. Mandel, S.R. Gullans, and S.P. Soltoff. 1984. Interactions between phosphate and oxidative metabolism in proximal renal tubule. Am. J. Physiol. 247:F575-F581.

31. Biber, J., M. Custer, A. Werner, B. Kaissling, and H. Murer. 1993. Localization of $\mathrm{NaPi}-1$, a $\mathrm{Na} / \mathrm{Pi}$ cotransporter, in rabbit kidney proximal tubules II. Localization by immunohistochemistry. Pflueg. Arch. Euro. J. Physiol. 424: 210-215.

32. Loghman-Adham, M., G.T. Motock, P. Wilson, and M. Levi. 1995. Characterization of $\mathrm{Na}^{+}$-phosphate cotransporters in renal cortical endosomes. Am. J. Physiol. 268:F93-F102.

33. Ullrich, K.J., and H. Murer. 1982. Sulphate and phosphate transport in the renal proximal tubule. Philos. Trans. R. Soc. Lond. B Biol. Sci. 299:549-558.

34. Selz, T., J. Caverzasio, and J.P. Bonjour. 1989. Regulation of Na-dependent Pi transport by parathyroid hormone in osteoblast-like cells. Am. J. Physiol. 256:E93-E100.

35. Caverzasio, J., T. Selz, and J.P. Bonjour. 1988. Characteristics of phosphate transport in osteoblast-like cells. Calcif. Tissue Int. 48:83-87.

36. Garrett, I.R., B.F. Boyce, R.O.C. Oreffo, L. Bonewalde, J. Poser, and G.R. Mundy. 1990. Oxygen-derived free radicals stimulate osteoclastic bone resorption in rodent bone in vitro and in vivo. J. Clin. Invest. 85:632-639.

37. Dodds, R.A., M. Gowen, and J.N. Bradbeer. 1994. Microcytophotometric analysis of human OC metabolism: lack of activity in certain oxidative pathways indicates inability to sustain biosynthesis during resorption. J. Histochem. Cytochem. 42:599-606. 